\title{
The Use of Hydrothermal Carbonization to Recycle Nutrients in Algal Biofuel Production
}

\author{
Robert B. Levine, ${ }^{a}$ Christian 0. Sambolin Sierra, ${ }^{a}$ Ryan Hockstad, ${ }^{a}$ Wassim Obeid, ${ }^{b}$ \\ Patrick G. Hatcher, ${ }^{b}$ and Phillip E. Savage ${ }^{a}$ \\ ${ }^{a}$ Department of Chemical Engineering, University of Michigan, 2300 Hayward Drive, 3074 HH Dow, Ann Arbor, MI 48109; \\ psavage@umich.edu (for correspondence) \\ ${ }^{\mathrm{b}}$ Department of Chemistry and Biochemistry, Old Dominion University, 4402 Elkhorn Ave., Norfolk, VA 23529
}

Published online 24 July 2013 in Wiley Online Library (wileyonlinelibrary.com). DOI 10.1002/ep.11812

\begin{abstract}
The high fertilizer demand for biodiesel production from microalgae is a significant challenge facing the commercialization of this promising technology. We investigated a processing strategy called bydrothermal carbonization (HTC) to convert wet algal biomass into a lipid-rich hydrochar and aqueous phase (AP) co-product. By reacting biomass at $200^{\circ} \mathrm{C}$ for $15 \mathrm{~min}$, about 50\% of the algae biomass became a solid hydrochar and roughly $40-70 \%$ of the $C, N$, and $P$ in the reactant material dissolved into the AP. For the first time, an AP COproduct of this nature was analyzed by HPLC, GC-MS and FTICR-MS to identify and characterize the dissolved organic matter. Using a unique marine bi-culture suspected to contain a green algae (Nannochloris) and a cyanobacteria (Synechocystis), we demonstrated that this AP co-product can support biomass growth better than a medium containing only inorganic nutrients. To manage unwanted contamination and optimize AP utilization, we employed a two-stage growth process and fed-batch additions of the AP co-product. The effect of media recycling and nutrient supplementation, as well as a production model for a large-scale facility, are discussed. Our work suggests that HTC can play a critical role in making algal biorefineries more sustainable by obviating biomass drying for fuel processing and recycling nutrients. ( 2013 American Institute of Chemical Engineers Environ Prog, 32: 962-975, 2013

Keywords: hydrothermal carbonization; subcritical water bydrolysis; nutrient recycling; biodiesel; microalgae
\end{abstract}

\section{INTRODUCTION}

Photosynthetic microalgae are of interest as a biofuel feedstock due to their high productivity relative to terrestrial plants, their ability to assimilate carbon dioxide, and the opportunity to use non-arable land and non-fresh water resources in their cultivation. Although promising, myriad challenges have prevented the commercialization of algal biofuels at prices competitive with petroleum, and the sustainability of large-scale algal production facilities has been viewed with concern when one considers the amount of fertilizer, carbon dioxide, and fresh water they will require [1]. Careful nutrient (i.e., nitrogen, phosphorus) management at algal bio-refineries is essential from a sustainability perspec-

(ㄷ) 2013 American Institute of Chemical Engineers tive and will only continue to become more relevant as the industry expands.

A recent life-cycle assessment (LCA) estimated that fertilizer use could account for approximately $50 \%$ of the energy and greenhouse gas (GHG) emissions related to algal feedstock production [2]. In addition to becoming increasingly expensive, some fertilizer resources, such as phosphorus, are finite, mined resources [3]. Without on-site nutrient recycling, we estimate that the amount of $\mathrm{N}$ and $\mathrm{P}$ fertilizers required to produce enough algal biomass to replace $20 \%$ of US transportation fuels is about 160 and $275 \%$, respectively, of the total use of these fertilizer resources in the US today (Table 1) [4,5]. In addition, if the N-rich, non-oil biomass is sold as an animal feed co-product, as many have proposed, this level of production would result in more than 10 times the amount of oilseed meal currently used in all US animal feeds today [6]. While wastewater may be able to help meet some of this fertilizer demand $[2,7,8]$, these data suggest that algal bio-refineries cannot afford to export nutrients in the form of nonfuel co-products but rather must efficiently reuse nutrients while producing biofuels.

Recently, we reported on a process to convert wet algal biomass into biodiesel using hydrothermal carbonization (HTC) and uncatalyzed, supercritical in situ (trans)esterification (SC-IST) [9]. In this process, described in Figure 1, algae are grown and then dewatered to produce a 10-25 wt \% total solids slurry that is reacted in and with hot liquid water $\left(190-250^{\circ} \mathrm{C}\right)$ at autogenic pressures to conglomerate cells into an easily filterable solid that retains the lipids (i.e., carbonized solids or hydrochar) and produce a sterile, nutrient-rich aqueous phase (AP). We previously demonstrated that the lipids within the hydrochar could be converted into biodiesel without prior solvent extraction by use of supercritical ethanol [10] or triflate-catalyzed in situ transesterification [11]. Here, we focus on the composition of the AP produced during HTC and its utility as a nutrient source for algal biomass production.

Interest has grown in using the $\mathrm{AP}$ generated during hydrothermal processing of wet algal biomass as a nutrient source for producing additional algal biomass. Early worked carried out on hydrothermal gasification [12,13] along with more recent advances in hydrothermal liquefaction [14,15] have demonstrated that certain algae are capable of growing on the dissolved nutrients in the AP co-product. These efforts all processed algal biomass at $350^{\circ} \mathrm{C}$ for varying amounts of time, separated the unreacted solids and bio-oil (in some 
Table 1. Fertilizer consumption and non-oil product generation related to producing $20 \%$ of US transportation fuels from algae without nutrient recycling.

\begin{tabular}{|c|c|c|c|c|}
\hline \multirow[b]{2}{*}{ Fuel type } & \multirow{2}{*}{$\begin{array}{c}\text { Total US } \\
\text { fuel consumption } \\
(1000 \mathrm{bbl} / \mathrm{yr})\end{array}$} & \multicolumn{2}{|c|}{$\begin{array}{l}\text { Fertilizer use for algal fuels } \\
1000 \mathrm{MT} / \mathrm{yr} \text { ( } \% \text { of US total) }\end{array}$} & \multirow{2}{*}{$\begin{array}{c}\text { Non-oil product } \\
\text { generated } 1000 \mathrm{MT} / \mathrm{yr} \\
(\% \text { of US total) }\end{array}$} \\
\hline & & Nitrogen & Phosphorus & \\
\hline Motor gasoline & $3,185,312$ & $12,000(98)$ & 3000 (168) & $224,800(649)$ \\
\hline Distillate fuels & 512,203 & 2200 & $600(31)$ & $41,500(120)$ \\
\hline Jet fuels & $1,369,835$ & $5600(45)$ & $1400(78)$ & $104,500(302)$ \\
\hline Combined & $5,067,350$ & $19,800(160)$ & $4900(275)$ & $370,900(1070)$ \\
\hline
\end{tabular}

Note: Algal biomass is assumed to contain $25 \%$ oil, $75 \%$ non-oil material, $4 \% \mathrm{~N}$, and 1\% P. Volumetric petroleum consumption data for 2012 [4] was converted into weight by assuming densities of 740,850 , and $800 \mathrm{~kg} / \mathrm{m}^{3}$ for motor gasoline, distillate fuels, and jet fuels, respectively. Algal oil is assumed to directly replace each fuel with no change in mass and no losses during processing. The basis for percentages are the total use of $\mathrm{N}$ and $\mathrm{P}$ fertilizer in US agriculture [5] and total oilseed meal consumed as animal feed in 2012 [6].

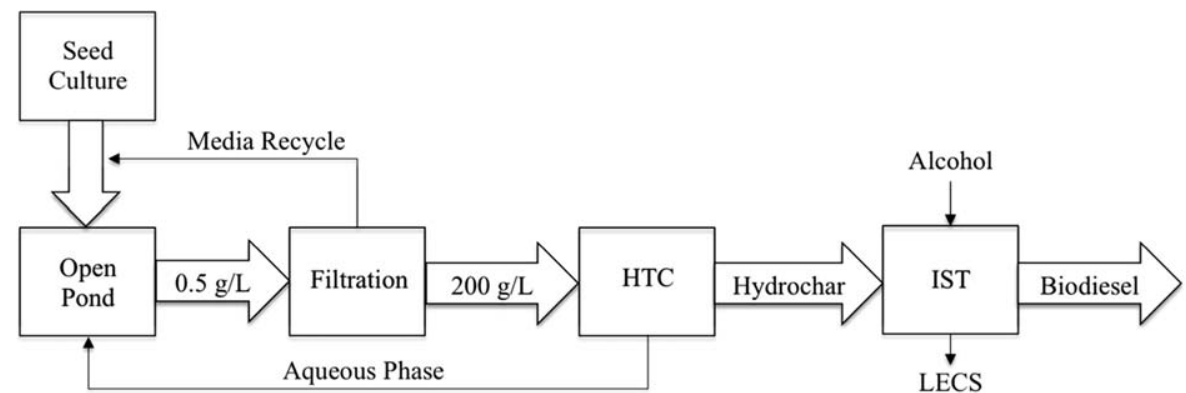

Figure 1. Process flow diagram of algal bio-refinery using hydrothermal carbonization (HTC) to recycle nutrients. Hydrochar produced by HTC undergoes in situ transesterification (IST) to produce biodiesel and lipid-extracted carbonized solids (LECS).

cases with organic solvents), and then diluted the aqueous phase 50 to 500 -fold to test its ability to support algal growth. In general, growth was greatest in the most dilute solutions, probably since dilution reduces the concentration of potential inhibitors such as ammonia, phenols, fatty acids, and metal catalyst residues. However, in cultures grown on diluted AP, biomass density only reached about 12\% [12], $50 \%$ [15], or $85 \%$ [14] of the density that was achieved when grown on standard media. These data suggest that the presence of inhibitors and the unequal dissolution of certain nutrients into the AP, such as nitrogen, phosphorus, and trace metals, could contribute to low overall biomass yields when using AP as a growth medium.

In an effort to reduce the concentration of inhibitors generated during subcritical water hydrolysis and preserve the nutrient quality of the AP, we have focused on HTC reactions carried out near $200^{\circ} \mathrm{C}$ for $15-30 \mathrm{~min}$. To our knowledge, only two previous studies have tested the efficacy of the AP co-product from algal biomass treatment at these temperatures as a nutrient source. Heilmann et al. [16] noted that about $45 \%$ of the carbon, $80 \%$ of the nitrogen, and $100 \%$ of the phosphorus from the reactant biomass (Chlamydomonas reinhardtii) could be recovered in the $\mathrm{AP}$ after a $2 \mathrm{~h}$ reaction at $200^{\circ} \mathrm{C}$. This extended reaction time reportedly led to the formation of nitrogen-containing Maillard-type heterocyclic compounds and piperazinediones (cyclic amino acid dimers). A 20-fold dilution of this AP was able to support growth of $C$. reinhardtii to about half the density reached when using tris-acetate-phosphate (TAP) medium. In experiments with a wild isolate of Chlorella, Du et al. [17] demon- strated that growth in 50, 100, and 200-fold dilutions of AP produced after a $40 \mathrm{~min}$ reaction at $200^{\circ} \mathrm{C}$ led to higher final biomass densities compared to cultures grown in BG-11, a medium containing no organic carbon. These experiments employed autoclaved media in small shaker flasks that were incubated under continuous illumination for 5-day batches.

While previous studies have focused on comparing algal growth rates when cultured with various dilutions of AP and common media formulations (e.g., TAP or BG-11), here we focus on the productivity of a two-stage growth system in which a nutrient-replete seed culture (stage 1) is used to inoculate larger production reactors that receive AP (stage 2). In this system, the dilution of the AP is intrinsically determined since all of the biomass harvested from the second stage is reacted to produce AP that is returned to that stage. We note that this approach is distinguished from what many in the field refer to as a two-stage cultivation strategy involving a nutrient replete stage for biomass growth and a nutrient deficient stage for lipid accumulation. A model biomass (Nannochloropsis oculata) was reacted at various conditions to identify the optimal combination of reaction temperature and time that results in high lipid yields and nutrient partitioning to the AP co-product. A unique bi-culture of a marine microalgae and a cyanobacteria developed in our laboratory was grown in bubble column reactors (BCRs) to study how $\mathrm{C}, \mathrm{N}$, and $\mathrm{P}$ liberated from the biomass during HTC could be recycled for algal growth. The effect of media recycling and nutrient supplementation, as well as the design of a production facility to limit contamination and maximize productivity, are discussed. 


\section{MATERIAL AND METHODS}

\section{Culture Conditions}

A bi-culture of a marine green algae and cyanobacteria, tentatively identified as Nannochloris and Synechocystis, respectively, was developed in our lab by stressing an open raceway culture of Nannochloropsis oculata with high concentrations of trace metals. The mixed culture was grown in a modified $\mathrm{f} / 2$ media containing brackish water $(27 \mathrm{~g} / \mathrm{L}$ Instant Ocean salt mix, Spectrum Brands) fortified with $\mathrm{N}$ (25$200 \mathrm{mg} / \mathrm{L}$ urea), $\mathrm{P}\left(50 \mathrm{mg} / \mathrm{L} \mathrm{NaH} \mathrm{PO}_{4} \cdot 2 \mathrm{H}_{2} \mathrm{O}\right)$, trace metals (1 $\mathrm{mL}$ stock solution/L final media), and vitamins (1 $\mathrm{mL}$ stock solution/L final media). The trace metal stock solution contained the following salts dissolved in $0.01 \mathrm{~N} \mathrm{H}_{2} \mathrm{SO}_{4}(\mathrm{mg} / \mathrm{L})$ : $\mathrm{Na}_{2}$ EDTA $2 \mathrm{H}_{2} \mathrm{O}$ (4360), $\mathrm{FeCl}_{3} \cdot 6 \mathrm{H}_{2} \mathrm{O}$ (3150), $\mathrm{MnCl}_{2} \cdot 4 \mathrm{H}_{2} \mathrm{O}$ (180), $\mathrm{ZnSO}_{4} \cdot 7 \mathrm{H}_{2} \mathrm{O} \quad(22), \quad \mathrm{CuSO}_{4} \cdot 5 \mathrm{H}_{2} \mathrm{O} \quad(10), \mathrm{CoCl}_{2} \cdot 6 \mathrm{H}_{2} \mathrm{O} \quad$ (10), $\mathrm{Na}_{2} \mathrm{MoO}_{4} \cdot 2 \mathrm{H}_{2} \mathrm{O}$ (6.3). The vitamin stock solution contained thiamin $\mathrm{HCl}(200 \mathrm{mg} / \mathrm{L})$, vitamin $\mathrm{B}_{12}(5 \mathrm{mg} / \mathrm{L})$, and biotin (5 $\mathrm{mg} / \mathrm{L}$ ). AP and various amounts of the nutrient supplements in the $f / 2$ media were used in different growth experiments, as described in "Biomass and Lipid Productivity in Two-Stage Production System with Nutrient Recycling" Section. In some experiments, a seed culture $(0.4$ to $1 \mathrm{~L})$ was diluted to the $4 \mathrm{~L}$ working volume of the BCRs with freshly prepared brackish water while in others spent media recovered after centrifugation was used for dilution to study the impact of continuous media recycling. Finally, when employing AP in the BCRs, Antifoam A concentrate (Sigma, $1-5 \mathrm{mg} / \mathrm{L}$ final concentration) was used to reduce foaming.

Cultures were maintained in $4 \mathrm{~L}$ polystyrene BCRs $(12.2 \mathrm{~cm}$ diameter $\times 50 \mathrm{~cm}$ tall) illuminated on a 14:10 h light:dark cycle with fluorescent bulbs $\left(\sim 300 \mu \mathrm{mol} / \mathrm{m}^{2}-\mathrm{s}\right)$ and stirred at $60 \mathrm{rpm}$. The BCRs were sparged with $2.5 \mathrm{~L} / \mathrm{min}$ air containing $\sim 1 \% \mathrm{CO}_{2}$ during the light hours or air during the dark hours. Each day a $14.5 \mathrm{~mL}$ sample was removed and centrifuged $(5000 \mathrm{RCF} \times 5 \mathrm{~min})$ and the cell-free supernatant was retained for analysis. The $\mathrm{pH}$ in the supernatant was measured immediately and then samples were typically frozen and maintained at $-4^{\circ} \mathrm{C}$. The pellet was washed with distilled $\mathrm{H}_{2} \mathrm{O}$ and transferred to a predried, preweighed glass tube where it was dried $\left(65^{\circ} \mathrm{C}\right.$ for at least $\left.24 \mathrm{~h}\right)$, allowed to cool in a desiccator, and then weighed. The solids in the glass tube were used for lipid analysis, as described in "Analysis of Lipids Within Algal Biomass and Hydrochars" Section.

\section{Hydrothermal Carbonization}

All carbonization reactions with wet algal biomass were carried out in 316 stainless steel (SS) reactors fashioned from Swagelok parts (two caps and one port connector). When biomass grown in BCRs was not yet available, we used $N$. oculata biomass ( $\sim 32 \%$ total solids as delivered) supplied by Reed Mariculture Inc. in carbonization experiments. This material was special ordered to be free of any preservatives and was stored frozen prior to use. Once the BCRs were fully functional, centrifugation was used to harvest biomass for HTC reactions. Typically, harvested biomass was immediately reacted to produce AP that could be recycled to the BCRs. Previously frozen or freshly harvested biomass was diluted to $\sim 15 \%$ total solids with distilled water and loaded by mass into the Swagelok reactors such that the reactor headspace was less than $10 \%$ of the total reactor volume under reaction conditions. Small $(4 \mathrm{~mL})$ reactors were used for initial HTC factorial experiments while larger $(28 \mathrm{~mL})$ reactors were used routinely for processing BCR harvests.

Once loaded, reactors were immersed in a preheated, isothermal fluidized sand bath for the desired amount of time and then promptly removed and cooled in water. Upon cooling, the reactors were emptied into $50 \mathrm{~mL}$ centrifuge tubes and $25 \mathrm{~mL}$ of distilled water were used to rinse the reactor housing. The reaction mixture was centrifuged (10,000 RCF $\times 5 \mathrm{~min}$ ) to pellet the hydrochar and the supernatant (i.e., aqueous phase) was transferred to a new tube. The solids were rinsed with $5 \mathrm{~mL}$ of distilled $\mathrm{H}_{2} \mathrm{O}$, briefly vortexed, and centrifuged again prior to drying $\left(65^{\circ} \mathrm{C}\right.$ for 24 h). The wash water was combined with the AP and the total volume of AP was diluted to $50 \mathrm{~mL}$ with distilled $\mathrm{H}_{2} \mathrm{O}$. Typically, multiple HTC reactions were pooled to produce enough diluted AP for growth experiments involving four BCRs, with some material being frozen for analysis.

The solids from each reaction were analyzed to determine the solids yield (g dry hydrochar/g dry biomass reacted), the lipid retention in the hydrochar (g lipid in hydrochar/g lipid in biomass reacted), and the elemental composition $(\mathrm{C}, \mathrm{H}, \mathrm{N}$ measured by Micro Analysis Inc.). The higher heating value ( $\mathrm{HHV}, \mathrm{MJ} / \mathrm{kg}$ ) of the reactant biomass and each hydrochar was estimated based on the elemental analysis according the following formula (Friedl et al.):[18]

$$
\begin{aligned}
\mathrm{HHV} & =\left(3.55 \mathrm{C}^{2}-232 \mathrm{C}-2230 \mathrm{H}+51.2 \mathrm{C} \times \mathrm{H}\right. \\
& +131 \mathrm{~N}+20,600) / 1000
\end{aligned}
$$

\section{Media and Aqueous Phase Analysis}

The cell-free supernatants taken from BCR samples and AP samples were analyzed for total organic carbon (TOC) using a Shimazdu TOC-V machine $(50 \mu \mathrm{L}$ injection, replicate injections made if standard error of peak area $>0.2 \%)$. AP samples were further analyzed using HPLC (Agilent 2100 series, $5 \mu \mathrm{L}$ injection onto a Phenominex ROA Organic Acids $7.8 \times 300 \mathrm{~mm}^{2}$ column at $60^{\circ} \mathrm{C}, 0.005 \mathrm{~N} \mathrm{H}_{2} \mathrm{SO}_{4}$ mobile phase, refractive index detector) and by GC-MS (Agilent $6890 \mathrm{~N}$ and $5973 \mathrm{~N}$ MSD, $1 \mu \mathrm{L}$ injection with 0 to $10: 1$ split ratio onto HP-InnoWax column J\&W $1909 \mathrm{BD}-113 ; 260^{\circ} \mathrm{C}$ inlet temperature, $40^{\circ} \mathrm{C}$ initial column temperature with $5^{\circ} \mathrm{C} / \mathrm{min}$ rise to $250^{\circ} \mathrm{C}$ ). The dissolved organic matter in the AP was further characterized using ultrahigh resolution Fourier transform ion cyclotron mass spectrometry (FT-ICR-MS). AP samples were diluted with 1:1 (v/v) methanol:water (LC-MS grade) and infused continuously into the Apollo II ESI ion source of a Bruker Daltonics 12 Tesla Apex Qe FT-ICR-MS at a rate of $2 \mu \mathrm{L} / \mathrm{min}$ (COSMIC facility at Old Dominion University). Shield and capillary voltages were optimized for each sample to maintain constant and stable ion currents in negative ion mode. Ions were accumulated in a hexapole for $1 \mathrm{~s}$ before being transferred to the ICR cell, where 300 scans collected with a 4-MegaWord time domain were co-added in broadband mode from $200-1200 \mathrm{~m} / z$. The summed FID signal was zero-filled once and Sine-Bell apodized prior to fast Fourier transform and magnitude calculation using the Bruker Daltonics Data Analysis software. Polyethylene glycol was used to externally calibrate the instrument to an accuracy of $<1 \mathrm{ppm}$ prior to analysis of samples. Internal calibration was performed on each sample using a peptide homologous series that was detected across all samples. Elemental formulae were assigned, with an accuracy of $<1$ ppm, using a Matlab program developed and described previously (Stubbins et al.).[19]

\section{Analysis of Lipids Within Algal Biomass and Hydrochars}

Lipids from all classes in algal biomass and carbonized solids were simultaneously extracted and catalytically (trans)esterified to determine the total lipid content, as described previously [11]. Briefly, solids were reacted with methanol containing 5\% acetyl chloride to produce fatty acid methyl esters (FAMEs), which were extracted into $2 \mathrm{~mL}$ heptane containing an internal standard (100-250 mg/L tricosanoic 

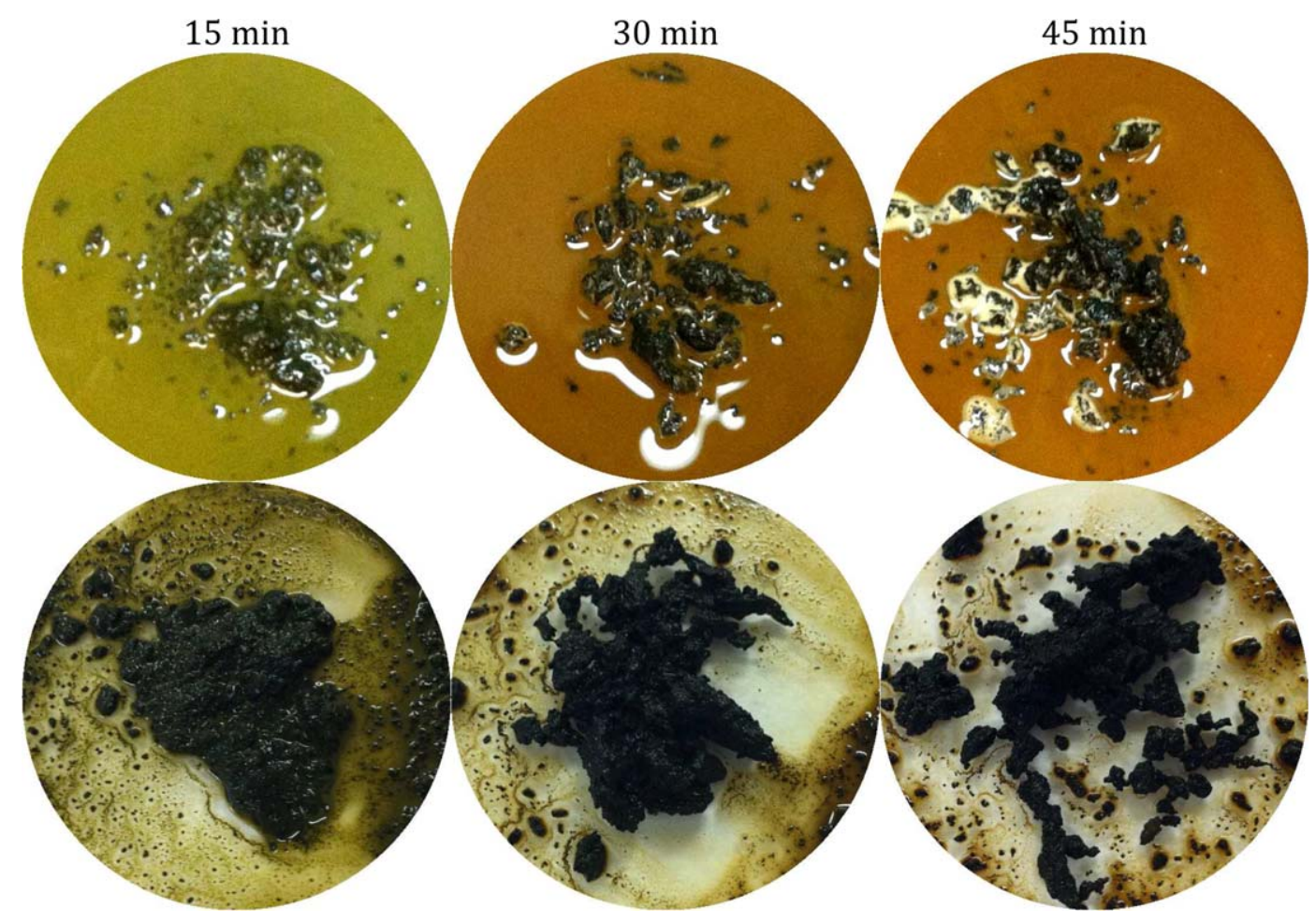

Figure 2. Hydrothermal carbonization of Nannochloropsis oculata biomass at $215^{\circ} \mathrm{C}$ for 15 , 30 , or 45 min. The top row shows the undiluted reactor contents following HTC. The bottom row shows the hydrochar after the aqueous phase has been poured off and highlights how reaction time can impact solids characteristics. Reactions carried out in $30 \mathrm{~mL}$ reactors with $23 \mathrm{~g}$ paste at $15 \%$ solids. [Color figure can be viewed in the online issue, which is available at wileyonlinelibrary.com.]

methyl ester, C23:0 FAME) and analyzed by GC-FID. The retention time of each FAME was identified from a standard mix (Supelco® 37 Component FAME Mix) and peak area was converted into the mass quantity of each FAME by the following formula:

mg FAME $_{\mathrm{x}}$ in sample $=\left(\frac{\mathrm{mg} / \mathrm{L} \mathrm{C23:0} \mathrm{in} \mathrm{heptane}}{\text { area C23:0 }}\right)$

$(0.002 \mathrm{~L}$ heptane $)\left(\operatorname{area~FAME}_{\mathrm{x}}\right)\left(\mathrm{RRF}_{\mathrm{x}}\right)$

where RRF is a theoretical relative response factor calculated on the basis of the C23:0 FAME internal standard (Ackman and Sipos, 1964). The relative standard deviation of the internal standard area was less than $2 \%$.

\section{RESULTS AND DISCUSSION}

\section{Hydrothermal Carbonization}

A model biomass ( $N$. oculata) was reacted at $180-215^{\circ} \mathrm{C}$ for $15-45$ min to study how HTC conditions affect solids yield, lipid retention, and nutrient distribution to the AP. We utilized lower temperatures and shorter times than traditional liquefaction work to reduce the energy and pressure required for hydrothermal processing, diminish the concentration of inhibitory compounds in the AP that may form due to unwanted side reactions, and produce a solid product enriched in lipids that is easy to separate by filtration or centrifugation.

\section{Hydrochar Yield and Lipid Retention}

The character of the hydrochar solids and the ease at which they dewatered were easy to assess visually, as shown in Figure 2. This exploratory work at $215^{\circ} \mathrm{C}$ for 15,30 , or 45 min demonstrated that reaction time has an obvious effect on solids conglomeration and likewise on filterability.
As shown in Table 2, HTC of $N$. oculata biomass (15\% solids) resulted in solids yields ranging from 41 to 51\% with lipid retention in the hydrochar of $90-100 \%$. The solids yield tended to decrease with increasing temperature and reaction times, likely as a result of increased hydrolysis of biomass constituents. Lipid retention, on the other hand, increased with reaction severity up to $200^{\circ} \mathrm{C}$ but showed a slight decline at $210^{\circ} \mathrm{C}$ and $30 \mathrm{~min}$. We suspect the apparent maximum in lipid retention around $200^{\circ} \mathrm{C}$ and 15-30 min occurred due to the limited hydrolysis of polar and neutral lipids (e.g., phospholipids and triglycerides, respectively) as well the formation of hydrophobic char particles that strongly retained these lipids. These data compare favorably to the lipid retention $(\sim 80-90 \%)$ reported for similar carbonization experiments at $200^{\circ} \mathrm{C}$ with Nannochloropsis [18]. Importantly, our analysis revealed that eicosapentanoic acid (EPA), a valuable omega-3 lipid, was not selectively lost during HTC and had nearly identical retention values to the values reported in Table 2 for the total lipid fraction.

\section{Carbon, Nitrogen, and Phosphorus Partitioning}

One goal of HTC is to maximize the dissolution of nonlipid $\mathrm{C}, \mathrm{N}$, and $\mathrm{P}$ from one harvest of biomass into an $\mathrm{AP}$ co-product that can be used to grow more algal biomass. The elemental composition of the reactant biomass and the hydrochars from each reaction was used to calculate the retention of $\mathrm{C}, \mathrm{N}$, and $\mathrm{P}$ in each hydrochar. As shown in Table 2, the hydrochars produced under the conditions investigated retained about $50-60 \%$ and $31-49 \%$ of the $C$ and $\mathrm{N}$, respectively, of the original biomass. The phosphorus content of $N$. oculata biomass and the hydrochar produced at $200^{\circ} \mathrm{C} \times 15 \mathrm{~min}$ were measured by $\mathrm{ICP}$, revealing a $\mathrm{P}$ retention of $43 \%$. As processing of this same algae biomass at even harsher conditions $\left(250^{\circ} \mathrm{C}\right)$ resulted in $<1$ wt $\%$ of 
Table 2. Hydrothermal carbonization yields and hydrochar characteristics for Nannochloropsis oculata.

\begin{tabular}{|c|c|c|c|c|c|c|c|c|c|c|c|}
\hline \multirow{2}{*}{$\begin{array}{l}\text { Temp. } \\
\left({ }^{\circ} \mathrm{C}\right)\end{array}$} & \multirow{2}{*}{$\begin{array}{l}\text { Time } \\
\text { (min) }\end{array}$} & \multirow{2}{*}{$\begin{array}{l}\text { Solids } \\
\text { yield }^{\dagger}\end{array}$} & \multirow{2}{*}{$\begin{array}{c}\text { Lipid } \\
\text { content } \\
(w t \%)^{\dagger, \ddagger}\end{array}$} & \multirow{2}{*}{$\begin{array}{c}\text { Total lipid } \\
\text { retention } \\
(\%)^{\dagger}\end{array}$} & \multicolumn{3}{|c|}{$\begin{array}{l}\text { Elemental com- } \\
\text { position (wt \%) }\end{array}$} & \multirow{2}{*}{$\begin{array}{c}\text { HHV } \\
(\mathrm{MJ} / \mathrm{kg})\end{array}$} & \multicolumn{3}{|c|}{$\begin{array}{l}\text { Retention in hydro- } \\
\text { char (\% of biomass) }\end{array}$} \\
\hline & & & & & C & $\mathbf{H}$ & $\mathbf{N}$ & & C & $\mathbf{N}$ & HHV \\
\hline \multicolumn{2}{|c|}{ Algal Biomass } & & $10.7 \pm 0.1$ & & 49.9 & 8.0 & 8.5 & 20.6 & & & \\
\hline 180 & 15 & $51 \pm 0.3$ & $18.8 \pm 0.2$ & $90 \pm 1.3$ & 57.8 & 8.5 & 8.1 & 26.3 & 59.5 & 48.7 & 62.6 \\
\hline 180 & 30 & $49 \pm 0.3$ & $20.2 \pm 0.0$ & $92 \pm 0.7$ & 58.8 & 8.6 & 7.6 & 26.9 & 57.8 & 43.9 & 61.2 \\
\hline 190 & 15 & 51 & 16.9 & 97 & 58.7 & 8.6 & 7.4 & 26.8 & 60.1 & 44.4 & 63.5 \\
\hline 190 & 30 & $47 \pm 0.6$ & $22.3 \pm 0.3$ & $99 \pm 2.4$ & 59.2 & 8.6 & 7.2 & 27.1 & 55.6 & 39.9 & 58.9 \\
\hline 200 & 15 & $47 \pm 0.4$ & $22.9 \pm 0.1$ & $100 \pm 0.5$ & 59.8 & 8.5 & 6.8 & 27.3 & 55.4 & 36.7 & 58.6 \\
\hline 200 & 30 & $44 \pm 1.1$ & $24.4 \pm 0.1$ & $100 \pm 2.3$ & 59.7 & 8.4 & 6.9 & 27.3 & 51.3 & 34.8 & 54.2 \\
\hline 210 & 15 & $45 \pm 0.9$ & $23.5 \pm 0.7$ & $100 \pm 0.9$ & 60.5 & 8.7 & 7.0 & 28.0 & 56.1 & 38.2 & 60.0 \\
\hline 210 & 30 & $41 \pm 0.1$ & $25.4 \pm 0.3$ & $96 \pm 0.9$ & 61.2 & 8.7 & 6.5 & 28.4 & 49.7 & 30.8 & 53.4 \\
\hline
\end{tabular}

*According to the supplier, $N$. oculata biomass contains $58.6 \%$ protein, $14.5 \%$ lipids (10.5\% total fatty acids), $20 \%$ carbohydrates, and $5.9 \%$ ash.

${ }^{\dagger}$ Solids yield and lipid data are averages \pm standard error for replicate reactions carried out in $4 \mathrm{~mL}$ reactors.

${ }^{\ddagger}$ Lipid content reported as the weight percent of fatty acid methyl esters in the dry solid.

Table 3. Hydrochar yields and lipid content from hydrothermal carbonization $\left(200^{\circ} \mathrm{C}, 15 \mathrm{~min}\right)$ of algae grown in bubble column reactors.

\begin{tabular}{|c|c|c|c|c|}
\hline \multirow[b]{2}{*}{ Lipids } & \multicolumn{2}{|c|}{$\begin{array}{l}\text { N-replete } \\
\text { culture }\end{array}$} & \multicolumn{2}{|c|}{$\begin{array}{c}\text { Aqueous } \\
\text { phase }^{\dagger}\end{array}$} \\
\hline & Algae & Char & Algae & Char \\
\hline $\begin{array}{l}\text { Hydrochar } \\
\text { yield (wt \%) }\end{array}$ & - & 54 & - & 51 \\
\hline $\begin{array}{l}\text { Solids content } \\
\quad(\mathrm{wt} \%)^{\ddagger}\end{array}$ & 13 & 39 & 16 & 31 \\
\hline $\begin{array}{l}\text { Total FAMEs } \\
\text { (wt \%) }\end{array}$ & 8.8 & 15 & 18 & 34 \\
\hline $\begin{array}{l}\text { Lipid Retention } \\
\text { (\%) }\end{array}$ & - & 91 & - & 99 \\
\hline $\mathrm{C}$ retention (\%) & - & 63 & - & 62 \\
\hline $\mathrm{N}$ retention (\%) & - & 44 & - & 53 \\
\hline \multicolumn{5}{|c|}{ Fatty Acid Profile (\% of total FAMES) } \\
\hline C16:0 & 19 & 20 & 21 & 21 \\
\hline C16:1 & 1.7 & 1.9 & 1.7 & 1.7 \\
\hline $\mathrm{C} 17: 0+\mathrm{C} 17: 1$ & 12 & 12 & 8.1 & 7.8 \\
\hline C18:0 & 0.87 & 0.86 & 3.6 & 3.6 \\
\hline C18:1 & 2.3 & 2.4 & 25 & 26 \\
\hline C18:2 & 17 & 17 & 17 & 16 \\
\hline C18:3n3 + C18:3n6 & 35 & 34 & 17 & 16 \\
\hline
\end{tabular}

*Bubble column reactor (BCR) culture grown on $\mathrm{f} / 2$ media with $93 \mathrm{mg} / \mathrm{L} \mathrm{N}$ (urea) for 5 days to about $1 \mathrm{~g} / \mathrm{L}$ density, corresponding to the seed reactor in Figure 6a.

${ }^{\dagger} \mathrm{BCR}$ seeded with $1 \mathrm{~L}$ of the $\mathrm{N}$-replete culture and grown on AP for 6 days to about $1.5 \mathrm{~g} / \mathrm{L}$ density, as shown in Figures $6 \mathrm{a}$ and $6 \mathrm{~b}$.

${ }^{\ddagger}$ Solids content (wt.\%) given for algae paste as reacted and for wet hydrochar immediately following the reaction after centrifugation.

the biomass converted into gas-phase products [21], we assume that any $\mathrm{C}, \mathrm{N}$, and $\mathrm{P}$ not retained in the hydrochar dissolved in the AP.
Table 4. C, N, and P content in the aqueous phase co-product from hydrothermal carbonization ( $\mathrm{mg}$ in AP per $1 \mathrm{~g}$ dry weight reacted).

\begin{tabular}{lccc}
\hline Feedstock & C & N & P \\
\hline N. oculata & 223 & 39 & 5.3 \\
BCR-grown biomass (N-replete) & 192 & 45 & 5.5 \\
BCR-grown biomass (AP) & 190 & 20 & 5.5 \\
\hline
\end{tabular}

*Aqueous phase nutrient content estimated from the C, N, and $\mathrm{P}$ content of reacted algal biomass and hydrochars as determined by a CHN analyzer (Micro-Analysis, Inc.). Biomass $\mathrm{P}$ content and hydrochar $\mathrm{P}$ retention were assumed to be 0.9 and $43 \%$, respectively, for all samples although it was only measured for the reaction containing $N$. oculata. All data was obtained from reactions containing about $23 \mathrm{~g}$ of paste ( $\sim 15 \%$ solids) reacted at $200^{\circ} \mathrm{C}$ for $15 \mathrm{~min}$.

The $\mathrm{C}$ and $\mathrm{N}$ partitioning to the AP observed here are similar to those reported by Du et al., who also showed that the retention of $\mathrm{C}$ and $\mathrm{N}$ in Nannochloropsis hydrochars decreased with increasing temperatures or longer times [20]. Working with the same biomass we used, Valdez et al. showed that hydrothermal treatment at $250^{\circ} \mathrm{C}$ and $20-90 \mathrm{~min}$ led to about $30-40 \%, 66-82 \%$ and $76-85 \%$ of the initial biomass $\mathrm{C}, \mathrm{N}$, and $\mathrm{P}$, respectively, residing in the AP [21]. These data suggest that processing algal biomass at $200^{\circ} \mathrm{C}$ results in more $\mathrm{C}$ but similar amounts or slightly less $\mathrm{N}$ and $\mathrm{P}$ in the $\mathrm{AP}$ as compared to the AP generated during liquefaction at $250^{\circ} \mathrm{C}$

\section{Energy Densification and Yield}

Beyond releasing nutrients to the AP, HTC results in a densification of the algal biomass into a hydrochar with increased heating value. One way to quantify this effect is to calculate the energy densification ratio, which is the ratio of the heating value of the hydrochar product to that of the original biomass. For the conditions examined in Table 2, the energy densification ratio ranged from 1.2 to 1.3 and increased with temperature and reaction time. This is 


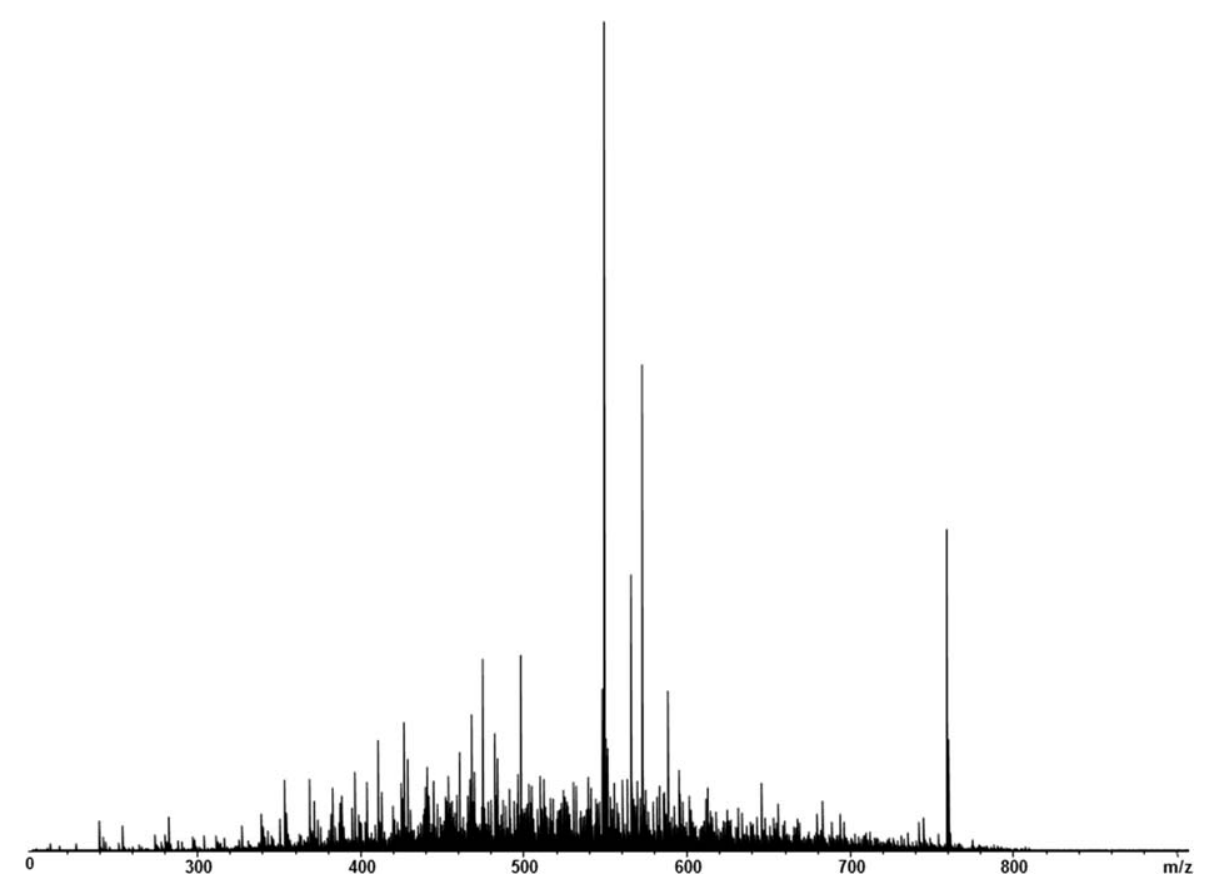

Figure 3. FT-ICR-MS spectra showing molecular weight distribution of organic matter in aqueous phase co-product obtained from reacting $N$. oculata biomass at $200^{\circ} \mathrm{C}$ for $15 \mathrm{~min}$.

comparable to the energy densification observed during the HTC of various algae [22] and lignocellulosic biomass [23]. Another important metric is the energy yield, which is defined as the solids yield multiplied by the energy densification ratio. Hydrochars contained between 53 and $63 \%$ of the energy content of the original biomass. These data indicate that $37-47 \%$ of the biomass energy is released as dissolved components in the AP, confirming that this byproduct from HTC is a potentially valuable source of nutrition and energy for growing algae. These data also highlight the opportunity presented by technologies such as catalytic hydrothermal gasification $[24,25]$, which can convert carbon in the AP into methane for on-site heat and power generation.

\section{Aqueous Phase Characterization}

The AP generated from $\mathrm{HTC}\left(200^{\circ} \mathrm{C}\right.$ for $\left.15 \mathrm{~min}\right)$ of the $N$. oculata biomass, biomass grown in the BCRs under nutrient replete conditions ( $\mathrm{f} / 2$ media with urea), and biomass grown in the BCRs with AP as a source of nutrients was characterized to determine the concentration of $\mathrm{C}, \mathrm{N}$, and $\mathrm{P}$ as well as the major chemical constituents of the dissolved organic matter. The two BCR-grown biomass samples were representative of the material produced in the first and second stages, respectively, of the proposed two-stage growth process and the resultant APs were employed in the growth experiment shown in Figure 6. A description of the HTC-related data for the BCR-grown biomass and the fatty acid profile of the feedstocks and hydrochar are given in Table 3. The AP data are described in Table 4 .

In general, the AP generated from the HTC of algal biomass was amber in color, had a $\mathrm{pH}$ between 5 and 6 , and emitted a foul odor. Most likely the odor arose from volatile components, such as short chain fatty acids. The C, N, and P contents of the AP were estimated from the elemental analysis of the feedstock and hydrochar. TOC measurements on the liquid AP samples were within $80-90 \%$ of the estimated total carbon content, suggesting that elemental analysis of process solids is an efficient and useful technique for evaluating the nutrient content of the AP co-product. As can be seen in Table 4, the AP is a rich source of $\mathrm{C}, \mathrm{N}$, and $\mathrm{P}$ that if bioavailable, could support a substantial amount of new biomass. The growth studies presented in "Biomass and Lipid Productivity in Two-Stage Production System with Nutrient Recycling" Section verify that the AP can indeed supply a large percentage of the nutrients required for algal growth.

To further identify components of the aqueous phase, we utilized HPLC, GC-MS, and FT-ICR-MS. HPLC detected various hydrolysis and decomposition products, mainly acetic acid, lactic acid, citric acid, pyroglutamic acid, glycerol, and limited amounts of furfurals. GC-MS revealed volatile organic acids (acetic, formic, propionic, and butanoic acids), short chain amides such as acetamide, heterocyclic compounds, such as 2-pyrrolidinone and butyrolactone, and several larger molecules tentatively identified as long chain crown ethers. By far, the largest peak detected on the GC-MS chromatogram and by HPLC was acetic acid, which corresponds to its refractory nature in hydrothermal environments [26]. Previous HTC work with loblolly pine has also found acetic acid to be the most prominent organic acid in the AP [27]. Fortunately, acetic acid is also a common carbon and energy source for mixotrophic and heterotrophic algal growth [28], and was previously found to be readily consumed in various algae growing on AP from hydrothermal liquefaction [14].

To gain a deeper understanding of the dissolved organic matter in the AP, FT-ICR-MS was employed. This analysis revealed a distribution of compounds with molecular weights ranging between 200 and $800 \mathrm{~m} / z$ (Figure 3). Further molecular characterization of the compounds revealed that $>86 \%$ of the peaks in each analyzed AP had molecular formulas containing the elements $\mathrm{C}, \mathrm{H}, \mathrm{O}$, and $\mathrm{N}$. It is quite notable that such a large percentage of the detected compounds contained $\mathrm{N}$. The extent to which algae can utilize organic N components is not precisely known, though several amino acids (e.g., glycine and glutamate) can serve as the sole $\mathrm{N}$ and $\mathrm{C}$ source for several algae, and we have observed the growth of many algae species on yeast extract alone, which is a mixture of material derived from lysing and heating yeast cells. In many ways, the use of AP to 


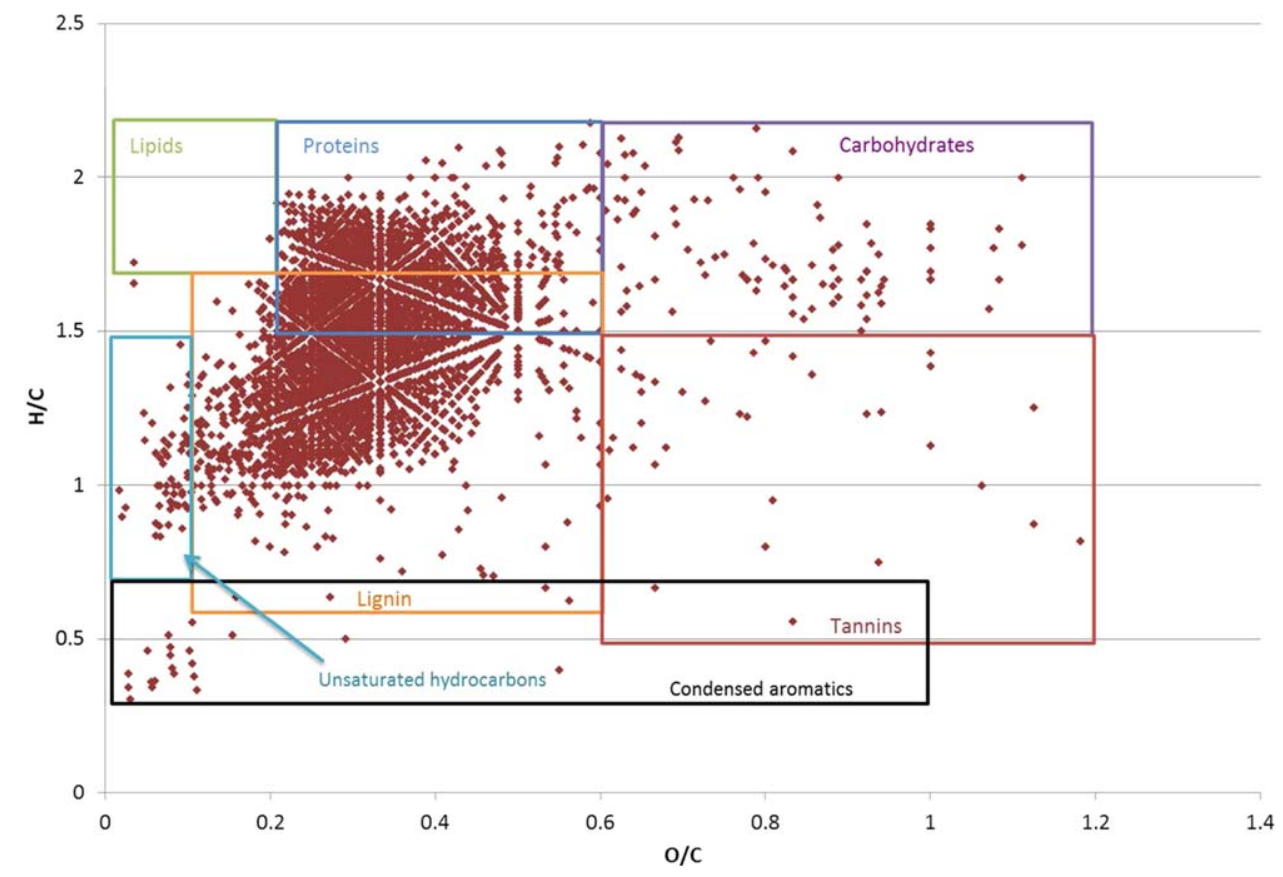

Figure 4. van Krevelen plot of organic compounds detected by FT-ICR-MS. The boundaries corresponding to representative compounds are highlighted. [Color figure can be viewed in the online issue, which is available at wileyonlinelibrary.com.]

a)

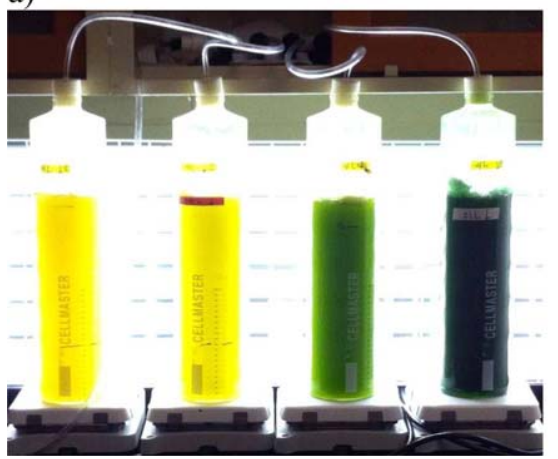

b)

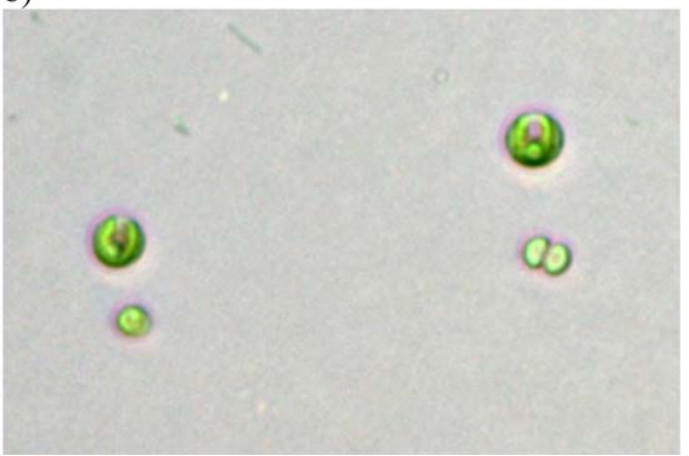

Figure 5. (a) Bubble column reactors (BCRs) in a nutrient replete state (green) and nutrient-deprived state (yellow); (b) light microscope image of bi-culture. Larger green algae cells were tentatively identified as Nannochloris, and smaller tealcolored cells, are suspected to be Synechocystis. The smaller spherical cells were commonly found to be dividing by fission, as shown on the right hand side. Minor bacterial contamination, typically in the form of rod-shaped cells, is evident in the upper left hand portion of the image. [Color figure can be viewed in the online issue, which is available at wileyonlinelibrary.com.]

grow algae is analogous to the use of yeast extract in many yeast and bacterial media. The growth experiments presented in the next Section would likewise suggest that the community of microorganisms present in the BCRs was adept at utilizing the $\mathrm{N}$ within the AP.

Placing the elemental composition of each compound detected on a van Krevelen plot helps to visualize that the major component of the organic matter in the AP appears to be protein-like compounds (Figure 4). Further analysis of the elemental ratios for the molecular formulas show that the majority of the compounds lies within the following ranges: $0.2-0.6 \mathrm{O} / \mathrm{C}, 1.5-2.2 \mathrm{H} / \mathrm{C}$, and $>0.05 \mathrm{~N} / \mathrm{C}$, which are typical for proteins. The small fraction of compounds that contained the elements $\mathrm{C}, \mathrm{H}, \mathrm{O}, \mathrm{N}, \mathrm{S}$, and $\mathrm{P}$ are likely to be phosphate or sulfate adducts.

\section{Biomass and Lipid Productivity in Two-Stage Produc- tion System with Nutrient Recycling}

\section{Culture Description and Preliminary Experiments}

Several growth experiments were carried out to determine the biomass and lipid productivity of a two-stage production system. We utilized a bi-culture that developed over time in our lab by stressing an outdoor open pond culture of Nannochloropsis with excessive metals (Figure 5). The metaltolerant species which emerged as stable members of the photosynthetic community were tentatively identified using light microscopy, anecdotal evidence from the pond operators, and literature values for the fatty acid profile of each species. This is the first time, to our knowledge, that the implications for biodiesel production of a bi-culture 
a)

Seed Reactor

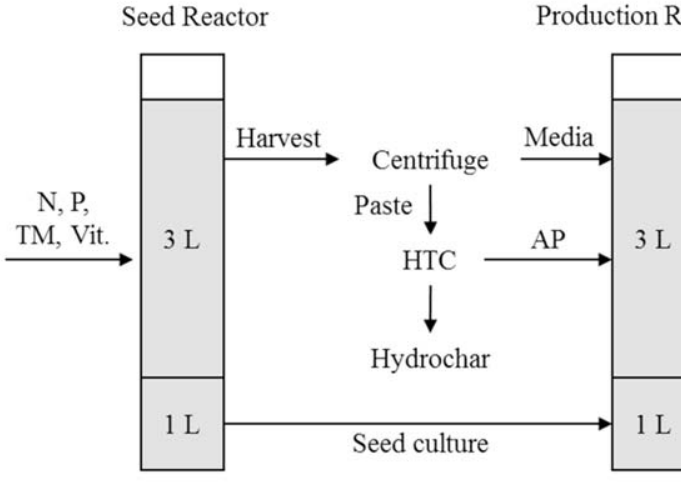

b)

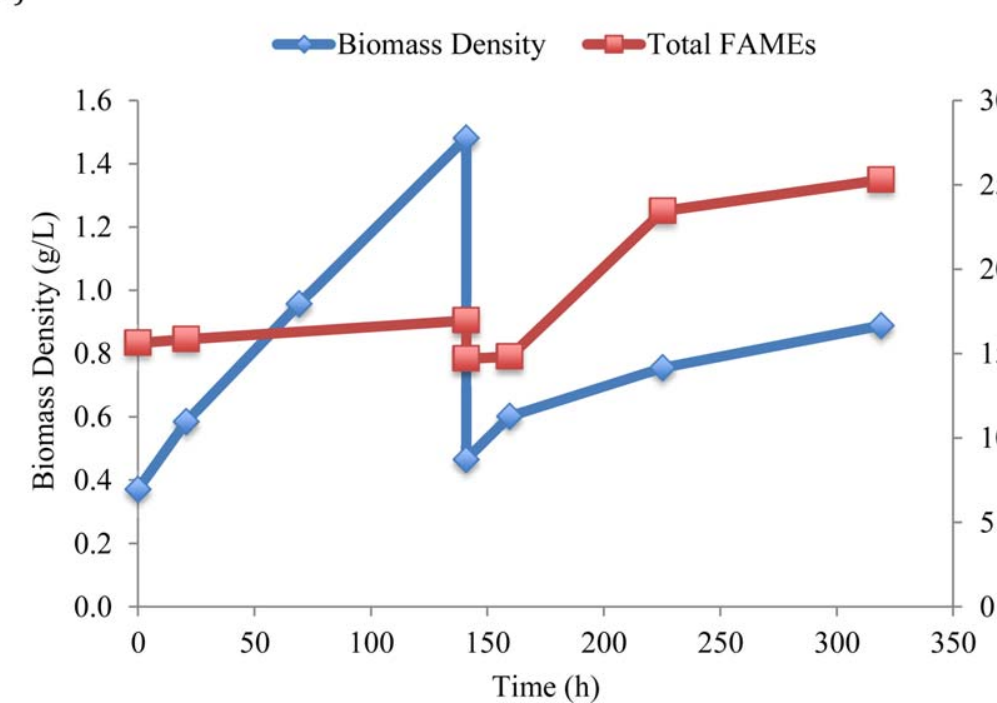

Production Reactor 2

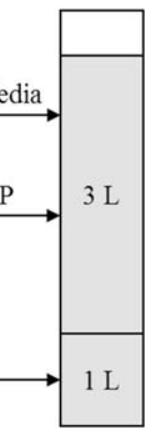

c)

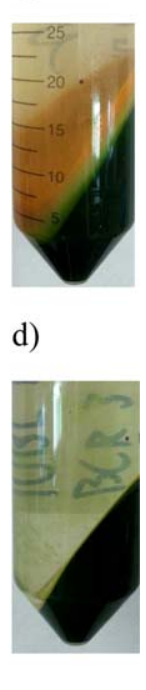

Figure 6. (a) Schematic of the repeat batch growth system utilized in this experiment. A 4 L bubble column reactor containing a 5-day old N-replete culture (grown on f/2 media with $93 \mathrm{mg} / \mathrm{L} \mathrm{N}$ as urea, $11 \mathrm{mg} / \mathrm{L} \mathrm{P}, 1 \times$ trace metals (TM) and vitamins) served as the seed reactor. A $1 \mathrm{~L}$ portion of the seed reactor was transferred to the first production reactor while the remaining $3 \mathrm{~L}$ were centrifuged to a paste and reacted to produce aqueous phase (AP, middle row of Table 4) for the first batch (0-141 h). At hour 141, $1 \mathrm{~L}$ of the first production reactor was transferred to a second production reactor while the remaining $3 \mathrm{~L}$ were centrifuged to a paste and reacted to produce AP (last row, Table 4) for the second batch (142-320 h). The liquid liberated by the centrifugation of both $3 \mathrm{~L}$ harvests was recycled without any pretreatment to the production BCRs and a small amount of make-up salt water was added to bring the initial volume of each BCR to $4 \mathrm{~L}$. (b) Biomass density and total lipid content over time in repeat batches containing AP. At the conclusion of the second batch $(320 \mathrm{~h}), 50 \mathrm{~mL}$ of the culture were centrifuged at 5000 RCF for 5 min (c) to observe non-algal material which appeared on top of the green pellet. This orange material was tentatively identified through light microscopy as bacteria and yeast cells and was compared to (d) a pellet obtained by centrifuging $50 \mathrm{~mL}$ of a 6 -day old seed reactor containing f/2 control media. [Color figure can be viewed in the online issue, which is available at wileyonlinelibrary.com.]

containing a green alga (Nannochloris), which is known to accumulate lipids during periods of nutrient stress [29,30], and a cyanobacteria (Synechocystis), which contains a basal lipid level and is most productive in nutrient replete conditions [31], have been explored. Both species have been shown to consume organic nutrients in both the light and dark [32-34], leading us to hypothesize that this multi-species community would be able to consume a greater variety of dissolved organic nutrients in the AP relative to what one organism could utilize alone. Several preliminary experiments were performed to demonstrate the stability of this biculture over time and ascertain appropriate concentrations of $\mathrm{N}$ and $\mathrm{P}$ in the $\mathrm{f} / 2$ media to support growth to about $1 \mathrm{~g} / \mathrm{L}$ biomass density.
In one preliminary experiment, we sought to demonstrate that media recycling and repetitive use of cultures grown on AP could be reliably carried out in our laboratory BCRs (Figure 6a). We grew $\mathrm{N}$-rich biomass in $\mathrm{f} / 2$ media containing 93 $\mathrm{mg} / \mathrm{L} \mathrm{N}$ as urea to produce a seed culture and AP for production BCRs. One liter of this culture was reserved as a seed for the experiment, while $3 \mathrm{~L}$ were harvested to produce paste for the HTC reaction (Table 3). The media liberated during centrifugation was returned to the BCR, most likely supplying a small amount of leftover $\mathrm{N}$ and $\mathrm{P}$. The AP was added (Table 4, middle row) and biomass growth and lipid content were tracked for almost 6 days (Figure 6b). During this time, biomass density increased steadily at an average rate of $7.9 \mathrm{mg} / \mathrm{L}-\mathrm{h}$ while the lipid content initially 


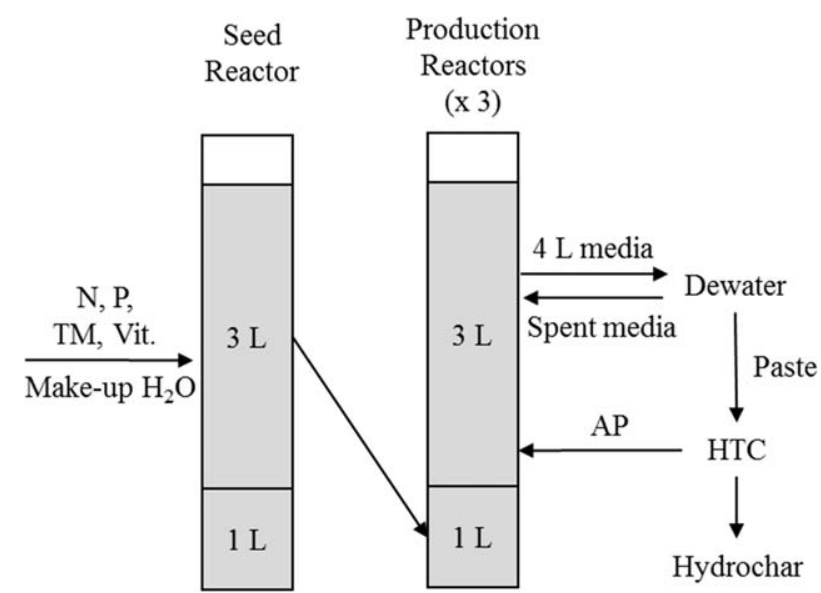

Figure 7. Schematic of proposed two-stage growth system with one repeat batch seed reactor and three batch or fedbatch production reactors. In this illustration, $75 \%$ of the seed reactor is used to seed three production reactors at $25 \%$ of their total volume while $25 \%$ of the seed reactor is retained to produce new seed material. These amounts are used here for illustration; in reality the proportions may vary. The seed reactor receives synthetic media components $(\mathrm{N}, \mathrm{P}$, trace metals (TM), and vitamins), along with make-up $\mathrm{H}_{2} \mathrm{O}$ to account for evaporative losses. The production reactors are initially filled with brackish water to their maximum volume $(4 \mathrm{~L})$, operated until the biomass density is about $1 \mathrm{~g} / \mathrm{L}$, and then the entire $4 \mathrm{~L}$ volume is harvested. The biomass is dewatered to produce a paste for HTC, which yields the aqueous phase (AP) co-product that is returned to the production reactors along with the spent media for subsequent batches. Additional nutrients can be added to the production reactors directly or by formulating a high strength medium for use in the seed reactor.

increased from about $10 \mathrm{wt} . \%$ in the seed culture to about 15 wt.\% and remained at this level for the duration of the batch. Three liters of this culture were then harvested to produce additional paste for HTC (Table 3), leaving $1 \mathrm{~L}$ behind as seed for the second batch. Again, the $3 \mathrm{~L}$ of spent media liberated during harvesting were returned to the BCR along with the AP (Table 4, last row).

As shown in Figure 6b, the biomass density increased over time in the second batch, albeit more slowly than in the first batch, but the lipid content climbed to $25 \%$ by the end of the experiment. Notably, the fatty acid profile of the biomass changed as lipids accumulated over time, as evidenced by comparing the columns in lower half of Table 3. These data reveal an increase in the proportion of oleic acid (C18:1), which is commonly associated with triglycerides in cytoplasmic oil bodies in green algae, and a decline in the proportion linolenic acid (C18:3), which is commonly found in polar membrane lipids [35,36]. This effect was even more pronounced at the conclusion of the second batch $(320 \mathrm{~h})$ when the lipid content was at a maximum. Most likely, biomass growth slowed and lipid accumulation occurred as a result of $\mathrm{N}$ limitation in the media since no supplemental $\mathrm{N}$ was added beyond what was in the AP. Based on the amount of new biomass generated during the second batch, its $\mathrm{N}$ content, and amount of $\mathrm{N}$ in the AP this $\mathrm{BCR}$ received, we estimate that about $75 \%$ of the $\mathrm{N}$ in the AP was utilized. It is also possible that the culture was inhibited due to refractory components in the AP or recycled media that became more concentrated in the second batch, though we have no direct evidence to support or refute this theory. In one case, spent media could reportedly be recycled up to four times in a a)

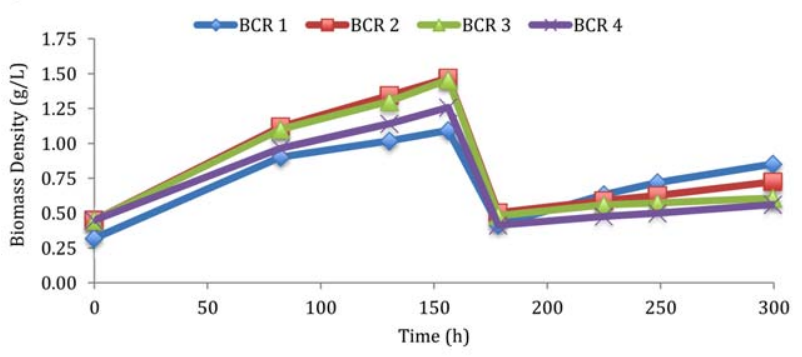

b)

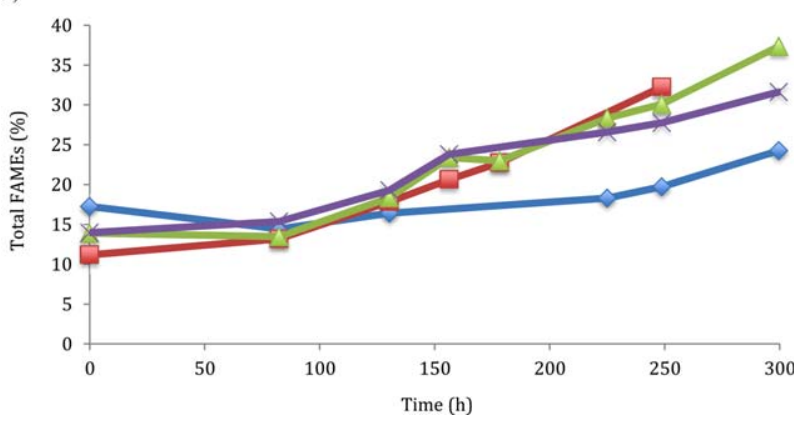

Figure 8. Biomass density (a) and lipid content (b) over time in cultures containing control media or AP with and without supplemental nutrients. Bubble column reactors (BCRs) contained $4 \mathrm{~L}$ total culture volume with the following components: (1) $\mathrm{f} / 2$ media with $17.5 \mathrm{mg} / \mathrm{L} \mathrm{N}$ as urea and $11 \mathrm{mg} / \mathrm{L} \mathrm{P}$; (2) f/2 media with $8.75 \mathrm{mg} / \mathrm{L} \mathrm{N}$ as urea, 5.5 $\mathrm{mg} / \mathrm{L} \mathrm{P}$, and $50 \mathrm{~mL} \mathrm{AP}$; (3) $8.75 \mathrm{mg} / \mathrm{L} \mathrm{N}$ as urea and $50 \mathrm{~mL}$ AP; (4) $50 \mathrm{~mL}$ AP. AP was generated by reacting $N$. oculata biomass at $200^{\circ} \mathrm{C}$ for $15 \mathrm{~min}$ (Table 4). Cultures were diluted $1: 4$ at $156 \mathrm{~h}$ to increase irradiance per cell. Lipid data for BCR 2 at $300 \mathrm{~h}$ was not available. [Color figure can be viewed in the online issue, which is available at wileyonlinelibrary.com.]

Nannochloropsis culture with no apparent effects on productivity [37]. Another possibility is that non-algal contamination, which was observed both microscopically as well as in an orange layer which appeared above the green algae pellet during centrifugation (Figures $6 \mathrm{c}$ and $6 \mathrm{~d}$ ), diminished growth rates through competition for nutrients, increased shading of photosynthetic cells, and/or the secretion of inhibitory substances. As the BCRs were not operated under sterile conditions and the AP was rich in organic nutrients, it is not surprising that after more than 13 days a variety of mostly heterotrophic contaminants (e.g., bacteria and yeast) were found in this culture.

Based on these results, we hypothesized that a two-stage production process would permit better control of contamination (Figure 7). In the first stage, a seed culture is grown on brackish water containing synthetic media components such as urea and sodium phosphate. The majority of this culture serves as the seed for several larger production reactors, while a fraction remains in the seed reactor to produce material for the next batch. The production reactors are filled to capacity with brackish water or recycled media from the previous harvest as well as AP derived from processing the previous harvest. As the AP typically contains about 50-60\% of the N and $\mathrm{P}$ of the reactant biomass and we seek to achieve roughly the same harvest density on each batch $(\sim 1 \mathrm{~g} / \mathrm{L})$, we expect that some supplemental $\mathrm{N}$ and $\mathrm{P}$ would be required in the production reactors. We envision that this supplemental $\mathrm{N}$ and $\mathrm{P}$ could be delivered directly to the production reactors at the time of seeding, perhaps by dissolving the chemicals in the AP 
Table 5. Media N content, biomass growth, and N uptake for the growth experiment shown in Figure 7 (up to 156 h).

\begin{tabular}{lllll}
\hline Metric & BCR 1 & BCR 2 & BCR 3 & BCR 4 \\
\hline Initial media N content from aqueous phase (mg/L) & 0.0 & 41.0 & 41.0 & 41.0 \\
Initial media N content from urea (mg/L) & 17.5 & 8.8 & 8.8 & 0.0 \\
New biomass (g/L) & 0.8 & 1.0 & 3.05 & 2.99 \\
Biomass N content at 156 hrs (wt \%) & 2.31 & 31.1 & 30.1 & 61 \\
Estimated N uptake (mg/L) & 17.9 & 62 & 52 & 56 \\
Estimated N uptake (\% of total) & 102 & 54 & 56 \\
Estimated N uptake (\% of N in aqueous phase) & - & & 56 \\
\hline
\end{tabular}

*Biomass $\mathrm{N}$ content measured by elemental analysis using CHN analyzer (Micro-Analysis, Inc.).

${ }^{\dagger}$ Estimated $\mathrm{N}$ uptake as a percentage of the $\mathrm{N}$ in the aqueous phase assumes that all urea present in the initial media was completely utilized and any remaining $\mathrm{N}$ assimilated into biomass was supplied by the aqueous phase.

prior to its addition, or be contained within the seed culture by formulating a high strength medium for the first stage. This two-stage growth process, which relies on repeat-batch and batch-processing, will likely afford better culture stability and more flexible harvest scheduling (i.e., batch time could readily be changed to account for diurnal and seasonal variability) compared to a continuous system. The impact on overall lipid productivity of supplemental $\mathrm{N}, \mathrm{P}$, and other media components, as well as media recycling and AP dosing, were therefore investigated.

\section{Biomass and Lipid Productivity with Model Aqueous Phase}

After these initial experiments, we next compared growth in the $\mathrm{f} / 2$ control media with growth in three treatments containing AP and various amounts of media supplements (Figure 8). As there was not sufficient biomass from a previous harvest to produce AP for this experiment, commercially available $N$. oculata was reacted $\left(200^{\circ} \mathrm{C}\right.$ for $\left.15 \mathrm{~min}\right)$ to produce AP (Table 4, top row). Each 4 L BCR was setup with a $1 \mathrm{~L}$ seed culture from a previous batch along with $3 \mathrm{~L}$ brackish water containing various amounts of $\mathrm{N}, \mathrm{P}$, trace metals, vitamins, and AP. BCR 1 contained the complete $\mathrm{f} / 2$ medium with $17.5 \mathrm{mg} / \mathrm{L} \mathrm{N}$ as urea, $11.2 \mathrm{mg} / \mathrm{L} \mathrm{P}$, and the normal amount of trace metals and vitamins. BCR 2 contained the complete $\mathrm{f} / 2$ media but with half the amount of $\mathrm{N}$ and $\mathrm{P}$ as BCR 1 plus $50 \mathrm{~mL}$ of AP. BCR 3 contained brackish water with $8.8 \mathrm{mg} / \mathrm{L} \mathrm{N}$ as urea, $50 \mathrm{~mL}$ of $\mathrm{AP}$, and no other media components. A final treatment (BCR 4) contained fresh brackish water with $50 \mathrm{~mL}$ AP. Each reactor received the same volume of AP, corresponding to the amount generated from harvesting and reacting $4 \mathrm{~L}$ of a $1 \mathrm{~g} / \mathrm{L}$ culture, and was estimated to add $234 \mathrm{mg} / \mathrm{L} \mathrm{C}, 41 \mathrm{mg} / \mathrm{L} \mathrm{N}$, and $5.5 \mathrm{mg} / \mathrm{L} \mathrm{P}$ to the initial media. In this experiment, BCR 1 was exemplary of the first stage of an algal biorefinery that we envision producing the seed culture for production reactors (BCRs 2-4).

It is apparent from Figure $8 \mathrm{a}$ that all treatments containing AP grew faster than the control media up until hour 156 , when the cultures were diluted to study the effect of higher per-cell irradiance on lipid accumulation. Most likely, AP led to higher growth rates and final densities by providing a source of organic nitrogen and as well as carbon that supported mixotrophic growth $[38,39]$. This outcome is similar to a recent report in which Nannochloris was found to grow significantly faster in $\mathrm{f} / 2$ media supplemented with yeast extract compared to $\mathrm{f} / 2$ media without organic nutrients [33]. Notably, there was very little difference in biomass density over time between the two treatments receiving AP plus supplemental N (BCRs 2 and 3), suggesting that the addition of $\mathrm{P}$, vitamins, and trace metals was not necessary to support growth at these levels. This is likely because the AP provides some of these nutrients and because added vitamins are superfluous in a mixed culture containing algae, cyanobacteria, and bacteria [40]. There was, however, a noticeable effect of the supplemental $\mathrm{N}$; the treatment that received only AP (BCR 4) grew to a slightly lower density by $156 \mathrm{~h}$ compared to AP-supplemented cultures receiving extra urea.

Based on the amount of $\mathrm{N}$ estimated to be in the initial media, the amount of new biomass generated, and the elemental composition of this biomass, we estimated the amount of $\mathrm{N}$ uptake which occurred during the first $156 \mathrm{~h}$ of growth (Table 5). In the control reactor (BCR 1), which did not contain AP, about $0.8 \mathrm{~g} / \mathrm{L}$ of new biomass containing about $2.3 \% \mathrm{~N}$ was generated by $156 \mathrm{~h}$. If we assume that all of the $\mathrm{N}$ in this new biomass was taken up from the media, then we estimate that slightly more than all of the urea initially present was consumed. Most likely, this minor over estimation is due to error associated with preparing the media, which could have led to slightly more urea being present initially, or error associated with determining the biomass density and its elemental composition. The complete utilization of $\mathrm{N}$ in the media was also apparent as the culture lost its green color and turned bright yellow by the third day. This process, termed chlorosis, is known to occur when $\mathrm{N}$ becomes limiting and the cell scavenges its internal N-rich components, such as green chlorophyll [41]. Similar observations were recorded about Nannochloropsis grown in nutrient-limited media in outdoor photobioreactors [42].

In the BCRs that received $\mathrm{AP}$, if we assume that any supplemental urea was utilized entirely, then about $52-56 \%$ of the $\mathrm{N}$ in the aqueous phase was incorporated into cell mass (Table 5). These cultures demonstrated signs of $\mathrm{N}$ limitation at $156 \mathrm{~h}$, evidenced by yellowing and some lipid accumulation (Figure 8b), even though the total $\mathrm{N}$ present in BCRs 2-4 could theoretically support 1.4-1.7 g/L of new biomass growth assuming $3 \% \mathrm{~N}$ in the biomass. These data suggest that only about $50-60 \%$ of the total $\mathrm{N}$ in the aqueous phase was utilized by the culture during this time period. We corroborated the elemental analysis of the AP N content presented in Table 4 by using Hach Kits to measure both the total nitrogen and ammonia-N present and found that about 55\% of the total $\mathrm{N}$ in the $\mathrm{AP}$ used in this experiment was in the inorganic ammonia form. Taken together, these data suggest that the algae readily consumed the inorganic $\mathrm{N}$ fraction of the AP during this 6.5 day cultivation.

With regards to the lipid content up to $156 \mathrm{~h}$, there was a slight accumulation of lipids in all treatments, with those receiving the most supplemental $\mathrm{N}$ having the lowest lipid content (Figure 8b). In the cultures with AP, the lipid content increased from about $15-23 \%$ total FAMEs. In the control media, the lipid content fluctuated between 15 and 19\%. At hour 156, each treatment was diluted by harvesting $3 \mathrm{~L}$ and 


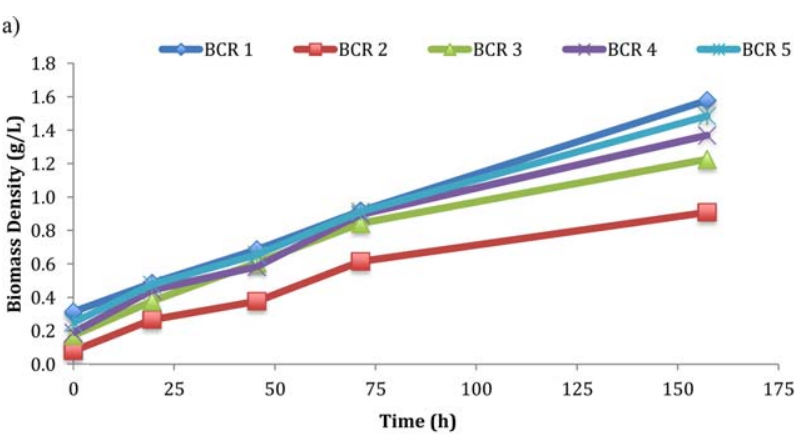

b)

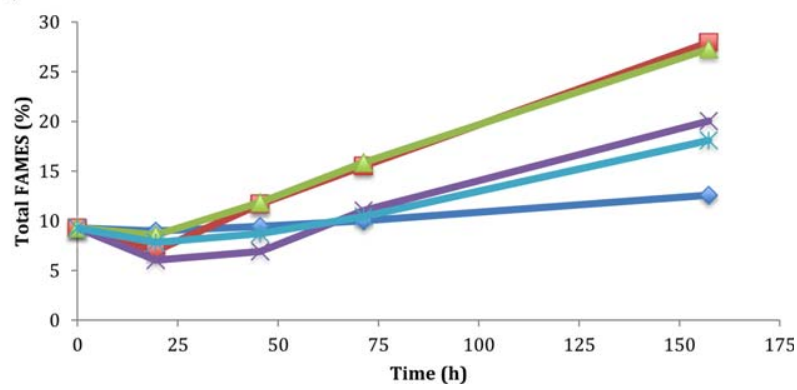

Figure 9. Biomass density (a) and lipid content (b) over time in cultures containing control media or AP with various seed sizes and recycled media. Bubble column reactors (BCRs) contained $4 \mathrm{~L}$ total culture volume with the following components: (1) f/2 media with $46 \mathrm{mg} / \mathrm{L} \mathrm{N}$ as urea and 11 $\mathrm{mg} / \mathrm{L}$ P; (2) $800 \mathrm{~mL}$ seed with fresh brackish water and AP; (3) $400 \mathrm{~mL}$ seed with fresh brackish water and AP; (4) 800 $\mathrm{mL}$ seed with recycled media and AP; (5) $400 \mathrm{~mL}$ seed with recycled media and AP. AP was generated by reacting BCRgrown N-replete biomass at $200^{\circ} \mathrm{C}$ for $15 \mathrm{~min}$. [Color figure can be viewed in the online issue, which is available at wileyonlinelibrary.com.]

refilling the BCR. In the case of the BCR 1 , new $\mathrm{f} / 2$ media was added exactly as was done at the beginning of the experiment. For the three other treatments, fresh brackish water was added with no other media ingredients. Following dilution, biomass density increased only very slightly in all treatments except for the control BCR, which doubled in density over the course of about $120 \mathrm{~h}$. This difference was expected since the control reactor received the complete $\mathrm{f} / 2$ media.

In the case of the reactors receiving $\mathrm{AP}$, the most growth occurred in BCR 2, the reactor receiving half the $\mathrm{N}$ and $\mathrm{P}$ of the control reactor as well as the full complement of $f / 2$ trace metals and vitamins. Following the dilution event, the biomass in all four reactors accumulated lipids, most likely as a result of higher irradiance per cell and nutrient limited conditions. Although the control reactor remained green until the end of the experiment and received extra $\mathrm{N}$ and $\mathrm{P}$, its lipid content increased to $24 \%$ at the conclusion of the experiment. This suggests that even without nitrogen limitation, increased irradiance can lead to higher lipid content as cells seek an electron sink to manage excess photons [43]. In the cultures receiving $\mathrm{AP}$, lipid accumulation was significantly greater than the control BCR, with the highest lipid content of 37\% being achieved in the BCR that received only AP and extra urea. These data are interesting as a comparison to what might be achievable in outdoor cultures exposed to substantially more light than our laboratory BCRs. Overall, it is likely that lipid productivity throughout this work was limited by the fluorescent lighting available. In the roughly 6 days leading up to the dilution event, lipid productivity was highest in the reactors receiving $\mathrm{AP}$ (i.e., 1.6, 1.8, $1.5 \mathrm{mg} / \mathrm{L}-\mathrm{h}$ for $\mathrm{BCRs} 2,3$ and 4 ). In comparison, the lipid productivity of the control reactor was about half, or $0.8 \mathrm{mg} / \mathrm{L}-\mathrm{h}$.

Biomass and Lipid Productivity with Self-Generated Aqueous Phase, Media Recycling, and Various Seed Volumes

Given the success of the previous experiment, which utilized an external source of algae to produce AP, we next repeated these experiments with AP co-product from hydrothermal treatment of the algae produced in our own BCRs. Although using AP produced by reacting lipid-rich biomass grown on AP is ideally how we envision the production reactors operating, the nature of our experimental setup limited our ability to produce such biomass in large enough quantities for subsequent studies. However, our first experiments (Figure 6) demonstrated that growth on AP produced from N-rich $(\sim 9 \%)$ and $\mathrm{N}$-poor $(\sim 3 \%)$ biomass can support a similar amount of new biomass when normalized for its $\mathrm{N}$ content. As a result, four BCRs were setup again with $\mathrm{f} / 2$ media containing $93 \mathrm{mg} / \mathrm{L} \mathrm{N}$ as urea to produce biomass for HTC reactions. Density in these reactors increased from about 0.3 to $1.1 \mathrm{~g} / \mathrm{L}$ over the course of $90 \mathrm{~h}$ while lipid content in the quickly growing cells remained roughly constant at about $10 \%$. The average biomass and lipid productivity over the $90 \mathrm{~h}$ period was $8.5 \pm 0.8$ and $0.72 \pm 0.06 \mathrm{mg} / \mathrm{L}-\mathrm{h}$, respectively. The biomass present at $90 \mathrm{~h}$ was used as a seed culture for four production reactors as well as another seed reactor (Figure 9). The remaining material was centrifuged to produce a paste that was reacted at $200^{\circ} \mathrm{C}$ for 15 min to make AP.

In this experiment, we sought to study the effect of media recycling and seed culture size in the second stage production reactors that are grown with $\mathrm{AP}$ and then completely harvested after 3-5 days. As with earlier experiments, the total culture volume of all the BCRs was initially $4 \mathrm{~L}$. The new seed reactor (BCR 1) received $1600 \mathrm{~mL}$ of seed culture and $2400 \mathrm{~mL}$ of complete $\mathrm{f} / 2$ media ( $46 \mathrm{mg} / \mathrm{L} \mathrm{N}$ as urea). The production reactors (BCRs 2-5) received either 400 or $800 \mathrm{~mL}$ of seed culture to serve as a 10 or $20 \%$ inoculum, respectively. To fill the reactors to $4 \mathrm{~L}$, BCRs 2 and 3 received fresh brackish water while BCRs 4 and 5 received recycled media from the previous harvest. This recycled media probably contained some additional $\mathrm{N}$ and $\mathrm{P}$ as well as cells that were not removed by centrifugation. Unlike previous experiments, in this one AP was added to BCRs 2-5 in a fed-batch process such that one third of the total AP dose was given on the first night and on each of the two evenings thereafter. The total amount of AP given to each BCR corresponded to harvesting and reacting $4 \mathrm{~L}$ of culture at about $0.85 \mathrm{~g} / \mathrm{L}$ density, which was equivalent to adding $164 \mathrm{mg} / \mathrm{L} \mathrm{C}$, $31 \mathrm{mg} / \mathrm{L} \mathrm{N}$, and $4 \mathrm{mg} / \mathrm{L} \mathrm{P}$ to each BCR. This strategy was adopted to reduce the concentration of excess organic carbon that may promote contamination, to preferentially supply carbon at night to promote heterotrophic growth and reduce biomass losses to respiration, and to limit the concentration of inhibiting compounds, should any be present.

As shown in Figure 9a, biomass density increased over time in all cultures, with the least growth observed in BCR 2. This reactor received the least amount of seed culture, so lower densities were expected. Although in a true production system we envision ponds containing AP running for only about 3-5 days, here we took daily observations up until 3 days and then allowed the cultures to continue to grow until day 6 in an effort to observe more distinct changes between them. As expected, the cultures that received recycled media reached a higher density than those receiving fresh seawater, most likely as a result of the excess urea present and the additional biomass that was not pelleted by centrifugation. Although all reactors were in effect supplemented with some amount of urea and $\mathrm{f} / 2$ media components from the seed culture, BCR 4 and 5 contained more due to the recycled media. These data suggest that recycling media for this length of time (about $250 \mathrm{~h}$ ) does not present a significant detriment due to the build-up of 
Table 6. Average Biomass and Lipid Productivities (mg/L-h) for Growth Experiments in Figure 9.

\begin{tabular}{lccccc}
\hline & \multicolumn{5}{c}{ Bubble column reactor } \\
\cline { 2 - 6 } & $\mathbf{1}$ & $\mathbf{2}$ & $\mathbf{3}$ & $\mathbf{4}$ & $\mathbf{5}$ \\
\hline Biomass productivity & & & & \\
$\quad$ 0-71 h & 8.4 & 7.5 & 9.4 & 9.9 & 9.3 \\
$\quad$ 0-157 h & 8.0 & 5.3 & 6.7 & 7.5 & 7.8 \\
Lipid productivity & & & & & \\
0 to 71 h & 0.8 & 1.2 & 1.6 & 1.2 & 1.0 \\
0 to $157 \mathrm{~h}$ & 1.0 & 1.6 & 2.0 & 1.7 & 1.6 \\
\hline
\end{tabular}

inhibitors. In addition, the densities achieved in BCR 2 and 3, which contained fresh brackish water, point to the importance of determining a suitable inoculum size to reduce the time until harvest densities are reached. The $20 \%$ inoculum reached $0.84 \mathrm{~g} / \mathrm{L}$ after 3 days compared to $0.6 \mathrm{~g} / \mathrm{L}$ for the $10 \%$ inoculum. The difference in density after 3 days between different seed culture sizes was much less pronounced in the reactors receiving recycled media, mostly likely as a result of the additional biomass present in the media.

The lipid content in each culture increased over time after a slight initial decline (Figure 9b). Notably, the two cultures receiving fresh brackish water and the two cultures receiving recycled media had very similar lipid contents, with the former being higher than the latter as a result of reduced nutrient content in the media. After 3 days, BCRs 2 and 3 contained about $16 \%$ lipids whereas BCRs 4 and 5 contained about $11 \%$ total FAMEs. As expected, the control reactor containing f/2 maintained a lipid content around $10 \%$ up until day 3 , after which point it increased slightly to $12.5 \%$. As shown in Table 6, lipid productivity was highest in BCR 3, which contained fresh seawater and 20\% inoculum. As the lipid productivity increased from 1.6 to 2.0 when considering 3 or 6 days, this suggests that it may be advantageous to run production reactors for longer than 3 days to achieve higher densities and lipid content. A similar correlation between batch length, biomass density, and lipid content has previously been reported for Nannochloropsis [37].

\section{Scale-Up Modeling}

The data collected throughout this work was used to create a production model for an algal bio-refinery producing about $3800 \mathrm{~m}^{3}$ (or 1,000,000 gallons) of biodiesel per year (Table 7). The model assumes there are two stages for biomass production: the first is the seed reactor that operates in repeat-batch mode to generate material for the second stage production reactors. Based on the results obtained from growth on $f / 2$ media with urea and no organic carbon sources (BCR 1 in Figure 9a and Table 6) and growth on AP (BCR 3 in Figure 9a and Table 6), biomass productivities of 8 and $7 \mathrm{~g} / \mathrm{m}^{3} / \mathrm{h}$ were chosen for the first and second stages of the model, respectively. At this rate, $90 \%$ of the seed reactor can be harvested every 5 days at about $1 \mathrm{~g} / \mathrm{L}$ biomass density. In the production reactors, the seed culture is diluted (1:5) and then grown for 5 days until the density of $1 \mathrm{~g} / \mathrm{L}$ is reached. This target biomass density was chosen since it appears to be achievable in open pond cultures, though it may be possible to reach significantly higher densities in photobioreactors [37]. Production reactors also receive the AP co-product arising from the HTC of the previous harvest. We envision a large-scale HTC reactor will process biomass paste continuously or semi-continuously, likely in a tubular reactor employing scraped-surface heat exchangers. As previously mentioned, since AP is rich in organic material, these production reactors are at a higher risk for contamination. To manage this risk, we assume that the entire volume of the production reactor will be harvested
Table 7. Production model for algal biorefinergy using twostage growth scheme to produce about one million gallons of biodiesel annually.

\begin{tabular}{|c|c|c|c|}
\hline Metric & Units & $\begin{array}{c}\text { Seed } \\
\text { reactors }\end{array}$ & $\begin{array}{c}\text { Production } \\
\text { reactors }\end{array}$ \\
\hline $\begin{array}{l}\text { Total culture } \\
\text { volume }\end{array}$ & $\mathrm{m}^{3}$ & 62,500 & 281,250 \\
\hline Batch inoculum & $\mathrm{m}^{3}$ & 6250 & 56,250 \\
\hline Batch length & hours & 120 & 120 \\
\hline $\begin{array}{l}\text { Average biomass } \\
\text { productivity }\end{array}$ & $\mathrm{g} / \mathrm{m}^{3} / \mathrm{h}$ & 8 & 7 \\
\hline $\begin{array}{l}\text { Biomass density } \\
\text { at harvest }\end{array}$ & $\mathrm{kg} / \mathrm{m}^{3}$ & 1 & 1 \\
\hline $\begin{array}{l}\text { Lipid content } \\
\text { at harvest }\end{array}$ & \% d.w. & 10 & 20 \\
\hline \multirow{2}{*}{$\begin{array}{l}\text { Biomass } \\
\text { production }\end{array}$} & MT/harvest & - & 300 \\
\hline & $\mathrm{MT} / \mathrm{yr}$ & - & 18,600 \\
\hline \multirow[t]{2}{*}{ Oil production } & MT/harvest & - & 60 \\
\hline & $\mathrm{MT} / \mathrm{yr}$ & - & 3700 \\
\hline \multirow{2}{*}{$\begin{array}{l}\text { Biodiesel } \\
\text { production }\end{array}$} & $\mathrm{MT} / \mathrm{yr}$ & - & 3400 \\
\hline & $\mathrm{m}^{3} / \mathrm{yr}$ & - & 3800 \\
\hline
\end{tabular}

Note: This model assumes that $90 \%$ of the volume of the seed reactor is transferred to the production reactors every 5 days to provide a $20 \%$ inoculum and that the entire contents of the production reactors are harvested at the end of each 5 days batch. It is assumed that 63 batches can occur per year in a location with ideal climatic conditions. The overall yield of biodiesel from algal oil is assumed to be $90 \%$ and biodiesel is assumed to have a density of $0.88 \mathrm{~kg} / \mathrm{L}$. Numbers rounded for clarity.

every 5 days. It may also be necessary to briefly disinfect the production reactors prior to beginning the next batch.

If both the seed and production reactors $\left(345,750 \mathrm{~m}^{3}\right)$ are taken to be $25 \mathrm{~cm}$ deep raceway ponds $\left(0.25 \mathrm{~m}^{3} / \mathrm{m}^{2}\right)$, then the total area required for cultivation is 137 ha. Based on the values shown in Table 7 for the annual lipid productivity, we estimate about $27 \mathrm{MT} / \mathrm{yr}$ of lipid can be produced per hectare of pond in a location permitting year-round operation. At 20\% lipid content in the harvested biomass, this amount is equivalent to about $37 \mathrm{~g} / \mathrm{m}^{2}$-day average annualized biomass productivity. If we assume that the mass yield of biodiesel on lipids is $90 \%$ (due to losses during HTC and/or transesterification) and the fuel has a density of $0.88 \mathrm{~kg} / \mathrm{L}$, this equates to about $28 \mathrm{~m}^{3}$ biodiesel/ha-yr (or 3000 gal biodiesel/acre$\mathrm{yr}$ ). This value is roughly half of recent estimates for bestcase lipid productivities, which ranged from 40.7 to $53.2 \mathrm{~m}^{3}$ oil/ha-yr depending on location [44], but about 50\% higher than the open-pond productivity of $25 \mathrm{~g} / \mathrm{m}^{2}$-day typically estimated for $20 \mathrm{~cm}$ deep ponds [45].

In general, our estimates for annual lipid production are higher than recent data collected from large-scale marine cultures carried out in outdoor photobioreactors, but do not appear unreasonable. For example, Rodolfi et al. [42] estimated that a two-stage growth system, in which $22 \%$ of the volume was devoted to nutrient sufficient growth and the remaining volume to lipid accumulation under nutrient deprivation, could yield 16-30 tonnes lipids/ha-yr depending on the latitude. In a similar work with Nannochloropsis in vertical photobioreactors, Quinn et al. [37] demonstrated average and peak lipid productivity of 7.04 and 21.1 or 13.1 and $36.3 \mathrm{~m}^{3}$ ha-yr for $N$. oculata and $N$. salina, respectively, 
in batches lasting between 3 and 26 days repeated over the course of 2 years. These repeat batches began with f/2 media containing $70 \mathrm{mg} / \mathrm{L} \mathrm{N}$ as $\mathrm{NaNO}_{3}$ and $11.4 \mathrm{mg} / \mathrm{L} \mathrm{P}$ and were carried out until biomass density reached $2-3 \mathrm{~g} / \mathrm{L}$ and the nitrogen in the media was exhausted. The peak productivities were recorded near the summer solstice (about June 20-22 each year), pointing to the significant impact that seasonal variability played on lipid production.

There are several reasons that our experimental biomass and lipid productivity data, when extrapolated to a large-scale facility, are higher than previously measured systems and cannot be directly compared. First and foremost, our data was collected in $4 \mathrm{~L}$ BCRs operating indoors under artificial illumination at near constant ambient temperatures. As a result, it likely over predicts the productivity that could be achieved in outdoor cultures and neglects the seasonal variability that would occur at most locations outside equatorial latitudes. Moreover, it is known that data collected from a single photobioreactor is not representative of the productivity of multiple systems due to shading from adjacent systems [37].

Conversely, this work is the first to report the productivity of a mixed community containing both a green algae and cyanobacteria that was grown in the presence of dissolved organic materials produced by hydrothermal carbonization. Recent work has demonstrated that in some cases an algal polyculture will yield more biomass than even its most productive species, a phenomena known as transgressive overyielding [46]. It is also well known that mixotrophic cultures, which can utilize solar energy as well as dissolved organic compounds, typically demonstrate higher productivity than purely phototrophic or heterotrophic systems [39]. This is particularly true in the case of cyclic autotrophic/heterotrophic cultures, in which a carbon source is added at the start of the dark period $[47,48]$. Nevertheless, the increased risk of contamination associated with adding organic carbon to an outdoor pond, along with the desire to capture the energy value of this carbon to create on-site heat and power, may incentivize the use of catalytic hydrothermal gasification or related technologies that can process the AP prior to its addition to the pond [24,25]. In this case, since dissolved carbon is converted into methane gas, one would expect very little additional benefit in productivity from mixotrophy relative to purely photosynthetic growth, but the AP would still serve to recycle N, P, and other nutrients. Our preliminary life-cycle assessment suggests that definitively capturing the energy value of the carbon in the AP helps improve the fossil energy ratio of the biodiesel produced and can likely eliminate the need to import electricity and natural gas for on-site operations.

\section{CONCLUSIONS}

This work has demonstrated that a marine bi-culture containing a green microalgae and a cyanobacteria can be grown as a biodiesel feedstock using nutrients liberated from its own biomass during hydrothermal carbonization. By dissolving biomass $\mathrm{C}, \mathrm{N}$, and $\mathrm{P}$ components into an aqueous phase co-product in such a way that these nutrients are bio-available, while simultaneously producing a lipid-rich hydrochar that can be converted into biodiesel, HTC can play a critical role in making algal biorefineries more sustainable. However, the use of AP must be appropriately managed to prevent unwanted contamination and optimize its utilization. By using a two-stage approach, where a clean seed culture is used to inoculate larger ponds receiving AP, our data suggest that high lipid productivities can be achieved relative to cultures grown only on inorganic media components. Future work should focus on long-term studies with multiple batches to determine if there are negative consequences to continual media recycling, such as the buildup of recalcitrant organics that do not get consumed, and expand this work to more species or multi-species mixtures to identify those most capable of growth on AP and recycled media.

\section{ACKNOWLEDGMENTS}

RBL acknowledges financial support from a NSF Graduate Research Fellowship and a University of Michigan Graham Environmental Sustainability Institute Fellowship. We also gratefully acknowledge financial support from the University of Michigan College of Engineering and from the U.S. National Science Foundation (CBET-1133439). We also thank Brian Goodall and Valicor Renewables for providing the initial open pond culture of Nannochloropsis that was used to generate our bi-culture.

\section{LITERATURE CITED}

1. Pate, R., Klise, G., \& Wu, B. (2011). Resource demand implications for US algae biofuels production scale-up. Applied Energy, 88, 3377-3388.

2. Clarens, A.F., Resurreccion, E.P., White, M.A., \& Colosi, L.M. (2010). Environmental life cycle comparison of algae to other bioenergy feedstocks. Environmental Science and Technology, 44, 1813-1819.

3. Cordell, D., Drangert, J.-O., \& White, S. (2009). The story of phosphorus: Global food security and food for thought. Global Environmental Change, 19, 292-305.

4. EIA. Monthy Energy Review. Available at: http:// www.eia.gov/totalenergy/data/monthly/\#renewabl. Access date of 05/01/2013.

5. USDA. (2013). Fertilizer Use and Price. Available at: http://www.ers.usda.gov/data-products/fertilizeruse-and-price.aspx\#26718. Access date of 05/01/2013.

6. USDA. (2013). Feed Grains: Yearbook Tables. Available at: $\quad<$ http://www.ers.usda.gov/data-products/feedgrains-database/feed-grains-yearbook-tables.aspx. Access date of 05/01/2013.

7. Pittman, J., Dean, A., \& Osundeko, O. (2011). The potential of sustainable algal biofuel production using wastewater resources. Bioresource Technology, 102, 17-25.

8. Levine, R.B., Costanza-Robinson, M.S., \& Spatafora, G.A. (2011). Neochloris oleoabundans grown on anaerobically digested dairy manure for concomitant nutrient removal and biodiesel feedstock production. Biomass and Bioenergy, 35, 40-49.

9. Levine, R.B., Pinnarat, T., \& Savage, P.E. (2010). Biodiesel production from wet algal biomass through in situ lipid hydrolysis and supercritical transesterification. Energy \& Fuels, 24, 5235-5243.

10. Levine, R.B., Bollas, A., \& Savage, P.E. (2013). Process improvements for the supercritical in situ transesterification of carbonized algal biomass. Bioresource Technology, 136, 556-564.

11. Levine, R.B., Bollas, A.A., Durham, M.D., \& Savage, P.E. (2012). Triflate-catalyzed (trans)esterification of lipids within carbonized algal biomass. Bioresource Technology, 111, 222-9.

12. Minowa, T., \& Sawayama, S. (1999). A novel microalgal system for energy production with nitrogen cycling. Fuel, 78, 1213-1215.

13. Tsukahara, K., Kimura, T.A.E., Minowa, T., Sawayama, S., Yagishita, T., Inoue, S., Hanaoka, T., \& Usui, Y. (2001). Microalgal cultivation in a solution recovered from the low-temperature catalytic gasification of the microalga. Journal of Bioscience and Bioengineering, 91, 311-313.

14. Biller, P., Ross, A.B., Skill, S.C., Lea-Langton, A., Balasundaram, B., Hall, C., Riley, R., \& Llewellyn, C.A. (2012). Nutrient recycling of aqueous phase for microalgae cultivation from the hydrothermal liquefaction process. Algal Research, 1, 70-76.

15. Jena, U., Vaidyanathan, N., Chinnasamy, S., \& Das, K.C. (2011). Evaluation of microalgae cultivation using recovered aqueous co-product from thermochemical liquefaction of algal biomass. Bioresource Technology, 102, 3380-3387. 
16. Heilmann, S.M., Jader, L.R., Harned, L.A., Sadowsky, M.J., Schendel, F.J., Lefebvre, P.A., Von Keitz, M.G., \& Valentas, K.J. (2011). Hydrothermal carbonization of microalgae II. Fatty acid, char, and algal nutrient products. Applied Energy, 88, 3286-3290.

17. Du, Z., Hu, B., Shi, A., Ma, X., Cheng, Y., Chen, P., Liu, Y., Lin, X., \& Ruan, R. (2012). Cultivation of a microalga Chlorella vulgaris using recycled aqueous phase nutrients from hydrothermal carbonization process. Bioresource Technology, 126, 354-7.

18. Friedl, A., Padouvas, E., Rotter, H., Varmuza, K., 2005. Prediction of heating values of biomass fuel from elemental composition. Analytica Chimica Acta 544, 191-198.

19. Friedl, A., Padouvas, E., Rotter, H., Varmuza, K., 2005. Prediction of heating values of biomass fuel from elemental composition. Analytica Chimica Acta 544, 191-198.

20. Du, Z., Mohr, M., Ma, X., Cheng, Y., Lin, X., Liu, Y., Zhou, W., Chen, P., \& Ruan, R. (2012). Hydrothermal pretreatment of microalgae for production of pyrolytic bio-oil with a low nitrogen content. Bioresource Technology, 111, 13-18.

21. Valdez, P.J., Nelson, M.C., Wang, H.Y., Lin, X.N., \& Savage, P.E. (2012). Hydrothermal liquefaction of Nannochloropsis sp.: Systematic study of process variables and analysis of the product fractions. Biomass and Bioenergy, 46, 317-331.

22. Heilmann, S.M., Davis, H.T., Jader, L.R., Lefebvre, P.A., Sadowsky, M.J., Schendel, F.J., Von Keitz, M.G., \& Valentas, K.J. (2010). Hydrothermal carbonization of microalgae. Biomass and Bioenergy, 34, 875-882.

23. Lynam, J.G., Toufiq Reza, M., Vasquez, V.R., \& Coronella, C.J. (2012). Effect of salt addition on hydrothermal carbonization of lignocellulosic biomass. Fuel, 99, 271-273.

24. Frank, E.D., Elgowainy, A., Han, J., \& Wang, Z. (2012). Life cycle comparison of hydrothermal liquefaction and lipid extraction pathways to renewable diesel from algae. Mitigation and Adaptation Strategies for Global Change, 18, 137-158.

25. Frank, E.D., Han, J., Palou-Rivera, I., Elgowainy, A., \& Wang, M.Q. (2012). Methane and nitrous oxide emissions affect the life-cycle analysis of algal biofuels. Environmental Research Letters, 7, 014030.

26. Meyer, J.C., Marrone, P.A., \& Tester, J.W. (1995). Acetic acid oxidation and hydrolysis in supercritical water. AIChE Journal, 41, 2108-2121.

27. Yan, W., Hastings, J., Acharjee, T., Coronella, C.J., \& Vasquez, V. (2010). Mass and energy balances of wet torrefaction of lignocellulosic biomass. Energy \& Fuels, 24, 4738-4742.

28. Perez-Garcia, O., \& Escalante, F. (2011). Heterotrophic cultures of microalgae: Metabolism and potential products. Water Research, 45, 11-36.

29. Takagi, M., Watanabe, K., Yamaberi, K., \& Yoshida, T. (2000). Limited feeding of potassium nitrate for intracellular lipid and triglyceride accumulation of Nannochloris sp . UTEX LB1999. Applied Microbiology and Biotechnology, 54, 112-117.

30. Yamaberi, K., Takagi, M., \& Yoshida, T. (1998). Nitrogen depletion for intracellular triglyceride accumulation to enhance liquefaction yield of marine microalgal cells into a fuel oil. Journal of Marine Biotechnology, 6, 44-48.

31. Rittmann, B.E. (2008). Opportunities for renewable bioenergy using microorganisms. Biotechnology and Bioengineering, 100, 203-212.

32. Thomas, W. (1966). Effects of temperature and illuminance on cell division rates of three species of tropical oceanic phytoplankton. Journal of Phycology, 2, 17-22.
33. Park, S., Choi, Y., Kim, E., Park, W., Kim, C., \& Yang, J. (2012). Serial optimization of biomass production using microalga Nannochloris oculata and corresponding lipid biosynthesis. Bioprocess and Biosystems Engineering, 35, 3-9.

34. Yang, C., Hua, Q., \& Shimizu, K. (2002). Integration of the information from gene expression and metabolic fluxes for the analysis of the regulatory mechanisms in Synechocystis. Applied Microbiology and Biotechnology, 58, 813-22.

35. Thompson, G.A. (1996). Lipids and membrane function in green algae. Biochimica et Biophysica Acta, 1302, 1745.

36. Harwood, J., \& Jones, A. (1989). Lipid metabolism in algae. Advances in Botanical Research, 16, 1-53.

37. Quinn, J.C., Yates, T., Douglas, N., Weyer, K., Butler, J., Bradley, T.H., \& Lammers, P.J. (2012). Nannochloropsis production metrics in a scalable outdoor photobioreactor for commercial applications. Bioresource Technology, $117,164-171$

38. Gim, G.H., Kim, J.K., Kim, H.S., Kathiravan, M.N., Yang, H., Jeong, S.-H., \& Kim, S.W. Comparison of biomass production and total lipid content of freshwater green microalgae cultivated under various culture conditions. Bioprocess and Biosystems Engineering, DOI: 10.1007/ s00449-013-0920-8.

39. Liang, Y., Sarkany, N., \& Cui, Y. (2009). Biomass and lipid productivities of Chlorella vulgaris under autotrophic, heterotrophic and mixotrophic growth conditions. Biotechnology Letters, 31, 1043-1049.

40. Droop, M.R. (2007). Vitamins, phytoplankton and bacteria: Symbiosis or scavenging? Journal of Plankton Research, 29, 107-113.

41. Gossauer, A., \& Engel, N. (1996). Chlorophyll catabolism-Structures, mechanisms, conversions. Journal of Photochemistry and Photobiology B: Biology, 32, 141-151.

42. Rodolfi, L., \& Zittelli, G.C. (2009). Microalgae for oil: Strain selection, induction of lipid synthesis and outdoor mass cultivation in a low-cost photobioreactor. Biotechnology and Bioengineering, 102, 100-112.

43. Hu, Q., Sommerfeld, M., Jarvis, E., Ghirardi, M., Posewitz, M., Seibert, M., \& Darzins, A. (2008). Microalgal triacylglycerols as feedstocks for biofuel production: Perspectives and advances. The Plant Journal, 54, 621-639.

44. Weyer, K., Bush, D., Darzins, A., \& Willson, B. (2010). Theoretical maximum algal oil production. Bioenergy Research, 3, 204-213.

45. Davis, R., Aden, A., \& Pienkos, P.T. (2011). Techno-economic analysis of autotrophic microalgae for fuel production. Applied Energy, 88, 3524-3531.

46. Cardinale, B.J., Matulich, K.L., Hooper, D.U., Byrnes, J.E., Duffy, E., Gamfeldt, L., Balvanera, P., O'Connor, M.I., \& Gonzalez, A. (2011). The functional role of producer diversity in ecosystems. American Journal of Botany, 98, $572-592$

47. Ogbonna, J.C., \& Tanakaah, H. (1998). Cyclic autotrophic/heterotrophic cultivation of photosynthetic cells: A method of achieving continuous cell growth under light/ dark cycles. Bioresource Technology, 65, 65-72.

48. Yang, C., Hua, Q., \& Shimizu, K. (2000). Energetics and carbon metabolism during growth of microalgal cells under photoautotrophic, mixotrophic and cyclic lightautotrophic/dark-heterotrophic conditions. Biochemical Engineering Journal, 6, 87-102. 